\title{
PRICE AND CAPACITY STRATEGIES IN THE EXPRESS DELIVERY SUPPLY CHAIN: ADVANCED PAYMENT, PENALTY OR TIME INSURANCE CONTRACTS
}

\author{
Kun Wang ${ }^{1, *}$, JuAnJuAn QIn ${ }^{2}$ And LiangJie Xia ${ }^{2}$
}

\begin{abstract}
In the Business to Consumer (B2C) environment, it is important to alleviate the mismatch between delivery capacity and demand in the express delivery supply chain. To do this, we propose three contracts to improve supply chain performance: the advanced payment contract, penalty contract, and time insurance contract. To assess these contracts, we considered the supply chain of one e-retailer and one express delivery provider. We discussed which contract is better for the supply chain partners when the three contracts can coordinate the supply chain. We found that when its unit cost of delayed orders is lower, the e-retailer will choose the advance payment contract among three contracts. When its unit cost of delayed orders is medium, the e-retailer will opt for the time insurance contract. When its unit cost of delayed orders is high, the e-retailer will not choose the advanced payment contract. In this case, whether the e-retailer chooses the time insurance contract and penalty contract depends on the value of wholesale price.
\end{abstract}

Mathematics Subject Classification. 90B50.

Received June 28, 2020. Accepted January 15, 2021.

\section{INTRODUCTION}

In certain periods, there are many e-retailers who reduce the retail prices to increase demand, such as China's Double-11 and USA'S Black Friday. The increase of demand puts forward a great demand for logistics service. From 2007 to 2009, consumer good sales through e-retail grew at a rate of $117 \%$, while total consumer good retail sales grew at an average rate of only $18 \%$ in China $[1,12]$. The total volume of delivered express packages in China exceeded 30 billion in 2016, ranking first in the world with total revenue of 354.47 billion Yuan. In China's Double-11 period, which refers to the large-scale shopping promotions offered on November 11 of each year, most e-retailers sell products at $50 \%$ off the normal price, resulting in a surge of online shopping. For example, during the Double-11 period in 2017, according to report by the State Post Bureau on November 12, e-commerce enterprises generated approximately 850 million express logistic orders a day. This was an increase of $29.4 \%$ over the same period during the previous year.

Keywords. Capacity strategy, express delivery supply chain, advanced payment contract, penalty contract, time insurance contract.

1 School of Business, Nankai University, Tianjin 300071, P.R. China.

2 School of Business, Tianjin University of Finance and Economics, Tianjin 300222, P.R. China.

* Corresponding author: haoyaun1314age@163.com 
To satisfy the demand of delivery service, the express delivery provider should make the investment decisions of the delivery capacity. If the capacity cannot satisfy the demand of delivery service, it brings negative effects on the partners' profits [18]. For example, deliveries may be delayed, damaged, or lost. This poor delivery service has created a bad consumer experience, diminishing their willingness to buy, and eventually hurting e-retailer profits $[40,43,45]$. As such, it is necessary to address the problem of mismatched demand and supply capacity within an express delivery supply chain.

To alleviate the mismatch between demand and capacity supply, the e-retailers and express delivery provider may introduce management measures, such as an advanced payment contract, a penalty contract, or a time insurance contract. We condense business practice cases into operational management issues and conduct valuable theoretical research. These are exactly the motivation of our work.

Advanced payment contract is widely used in the capacity reservation for high-tech manufacturer and its OEM customer [8]. More than 28 express delivery service providers have made the commitment: if the delivery service provider cannot meet commitment on delivery, consumers can transfer the logistics information feedback to the e-retailer. The e-retailer can initiate into the logistics order page to ask for punishment on the delivery service provider. Express company compensates according to the compensation standards (http://js.people.com. $\mathrm{cn} / \mathrm{html} / 2012 / 05 / 29 / 112673 . \mathrm{html})$. During the Double-11 period, e-retailers can purchase "Time Insurance" from SF Express, China's leading logistics service provider, at an additional cost of 5 Yuan; the insurance ensures that parcels can be delivered to the buyers within the promised time. If SF Express fails to deliver the parcels during the promised time, the e-retailer is exempted from the shipping cost and premium.

In the advanced payment contract, the e-retailer reserves delivery capacity before the demand occurs. In the penalty contract, the e-retailer penalizes the delivery service provider when the orders cannot be delivered on time. In the time insurance contract, the e-retailer pays an insurance premium to the express delivery provider. If the product is delayed, the express delivery provider returns the delivery fee and the insurance premium. Thus, the time insurance contract operates at time points both before and after the demand is realized.

This paper investigates how to solve the mismatch between the capacity supply and demand. Problems explored here are as follows:

(1) What are the e-retailer's price and express delivery provider's capacity strategies under the three contracts: the advanced payment contract, penalty contract, and time insurance contract?

(2) How do the three contracts coordinate the supply chain?

(3) Under what conditions will one contract dominate the others?

To answer these questions, we studied the price and capacity decision problem in one express delivery supply chain, consisting of a single e-retailer and a single delivery service provider. Three contracts are evaluated to address the mismatch in demand and supply: advanced payment contract, penalty contract and time insurance contract. First, we derive the equilibrium price and capacity decisions of the partners in the contracting schemes. Then, we discuss how the three contracts coordinate the supply chain. Finally, we compare the three contracts and discuss the contract choice made by the supply chain partners.

The novelty and innovation of our work are mainly reflected in three main ways. First, this is the first study to integrate the three contracts with different decisions at different time points in the express delivery supply chain. Second, we theoretically investigate the time insurance contract for the express delivery supply chain used by SF Express, with interesting outcomes. Third, we address the influence of the advanced payment contract in the express delivery supply chain. This step complements the current literature by focusing on the role of the advanced payment contract in the product supply chain.

The rest of this paper is organized as follows. Section 2 provides a literature review, and Section 3 presents the notation and assumptions made for this study. Section 4 addresses the decentralized model, in which, the eretailer and the express delivery provider make independent decisions. Section 5 discusses the centralized model, in which, the express delivery provider and the e-retailer are integrated as a single company to make decisions. In Section 6, we characterize the partners' optimal price and capacity decisions under the three contracts. Section 7 compares the three contracts. Section 8 presents the numerical analysis, to discuss the sensitivity analysis of the 
demand uncertainty and cost parameters on both participants' decisions and profits. Finally, key results and directions for future research are summarized in Section 9.

\section{LiteratuRE REVIEW}

There are three main streams of literature related to this research: logistical service supply chain, capacity strategies in the supply chain and supply chain contracts.

\subsection{Logistical service supply chain}

Many studies have focused on the supply chain associated with logistical services. Ellram et al. first proposed a service-oriented supply chain model. In a multi-periods logistical service supply chain [7], Liu et al. examined a coordinating mechanism, finding that a well-determined penalty helps ensure the quality of the logistics service [19]. Liu and Wang discussed a quality control game model in a logistical service supply chain based on different risk attitude combinations [18]. Liu et al. discussed procurement capacity in a logistical service supply chain with demand updates and expectations of rational behavior [22].

The closely related to our study is the research on a special logistical service: express delivery service. Qin et al. proposed a multilateral side-payment contract and a partial side-payment contract in the online shopping service supply chain, considering both fairness and individual rationality [29]. Zhang et al. analyzed the influence of an online hot selling period on an e-retailer's pricing strategies and the express delivery's service quality [43]. Liu et al. discussed methods for coordinating the express delivery supply chain with option contracts [21]. Liu et al. analyzed the coordination issues associated with the logistical service supply chain, investigating the impacts of the cost sharing contract on the logistics service supply chain [23]. However, few studies have discussed pricing and capacity strategies in express delivery supply chains under the contracts, such as advanced payment contract, penalty contract, or the time insurance contract.

\subsection{Capacity strategies in the supply chain}

Many studies have focused on the capacity strategies in the supply chain, such as capacity investment strategies and capacity procurement contract. VanMieghem provided are view of the capacity investment literature [37]. Recently, Liu et al. analyzed the when and how much to invest the capacity on producing batteries for electric vehicles [22]. Kong et al. explored the capacity investment model of wind power under uncertain supply price and high penetration rate [15]. Erkoc et al. discussed the equilibrium capacity investment for multinational manufacturer under uncertain exchange rate and competition [9]. In our study, we mainly focus on the capacity investment for the delivery service capacity in the supply chain considering the uncertain demand.

For capacity procurement contract, Wu et al. discussed $\alpha$-contract and capacity reservation contracts to study the horizontal capacity coordination [38]. Roels and Tang analyzed ex-post transfer payment contract and the ex-ante capacity reservation contract to address the capacity sharing strategy for the alliance [33]. Guo and $\mathrm{Wu}$ discussed the wholesale price contract for capacity-sharing strategy considering the horizontal competition [11]. Based on Guo and $\mathrm{Wu}$, Qin et al. analyzed the revenue sharing contract for horizontal capacity sharing strategies [30]. In our study, we investigate how to use the contracts to incentive the manufacture to improve its delivery service capacity under advanced payment contract, penalty contract, or the time insurance contract.

\subsection{Supply chain contracts}

In product-based manufacturing supply chains, many contracts have been explored to improve supply chain performance, such as advanced payment contract, penalty contract, and insurance contract. Tavakoli and Taleizadeh investigated the effect of advanced payment contracts on the ordered quantities of decaying items [36]. Chen et al. investigated the efficiency of early payment financing in a pull supply chain [5]. Balachandran and Radhakrishnan investigated a warranty/penalty contract between buyer and supplier based on information from incoming inspections and external failures [2]. Chen and Xiao discussed how an all-accepted penalty contract can be used to achieve a "win-win" situation between players [4]. Kusukawa and Alozawa discussed 
TABLE 1. Literature review.

\begin{tabular}{llll}
\hline \hline & Pricing strategies & Capacity strategies & Insurance contract \\
\hline Erkoc et al. $[9]$ & $\times$ & $\checkmark$ & $\times$ \\
Guo and Wu [11] & $\times$ & $\checkmark$ & $\times$ \\
Qin et al. $[29]$ & $\checkmark$ & $\times$ & $\times$ \\
Zhang et al. [43] & $\checkmark$ & $\times$ & $\times$ \\
Liu et al. $[23]$ & $\checkmark$ & $\times$ & $\times$ \\
Chen et al. $[5]$ & $\checkmark$ & $\times$ & $\times$ \\
Lukas et al. [24] & $\times$ & $\checkmark$ & $\times$ \\
Roels and Tang [33] & $\times$ & $\checkmark$ & $\times$ \\
Tavakoli and Taleizadeh [36] & $\checkmark$ & $\times$ & $\times$ \\
Kusukawa and Alozawa [16] & $\checkmark$ & $\times$ & $\times$ \\
Our study & $\checkmark$ & $\checkmark$ & $\checkmark$ \\
\hline
\end{tabular}

a reward-penalty contract to promote the collection and recycling of used products in a green supply chain [16]. Lin et al. analyzed an insurance contract in which the supplier shares the risk of overstock and understock with the retailer [17]. This improved supply chain efficiency with a newsvendor-type product. Other contracts that can improve supply chain performance include revenue sharing contract $[35,39,41]$ and options contract $[6,42,44]$.

In the express delivery supply chain, some contracts have been used to coordinate the supply chain, such as option contract [21], cost sharing contract [23]. But, few study discuss the three contracts in the delivery service supply chain, advanced payment contract, penalty contract, and insurance contract. Our research differs from others in three ways, which can be seen in Tab. 1.

\section{NotATION AND ASSUMPTIONS}

We consider an express delivery supply chain consisting of a single e-retailer and a single express delivery service provider. The e-retailer charges the consumer retail price $p$. The express delivery provider charges the e-retailer price $w$ for each unit of the express service.

Let $p$ be the retail price of the e-retailer. Market demand is expressed as:

$$
D=d+\varepsilon=a-\beta p+\varepsilon
$$

In this expression, $a$ is the total primary demand for the e-retailer, without considering the effect of the retail price; $\beta$ is the price sensitivity; the parameter $\varepsilon$ is the stochastic term, with the cumulative distribution function (C.D.F) $F(\varepsilon)$ and the probability density function (P.D.F) $f(\varepsilon)$. The stochastic parameter $\varepsilon$ is less than the deterministic demand $d$. This linear demand function is widely used $[20,34]$. We also refer to the literature that is helpful to our modeling [3,10,13,14,25-28,31,32].

The delivery capacity of the express delivery provider is denoted as $T$. The delivery service provider can accept and fulfill all orders; however, some orders are delayed when there is a shortage in the capacity of the delivery service provider. The term $Q_{1}(T)$ is defined as the expected quantity of the orders that arrive on time (or early) for a given $T$; the term $Q_{2}(T)$ is defined as the expected quantity of the orders that are delayed. This yields

$$
\begin{aligned}
Q_{1}(T) & =E(\min (D, T))=\int_{0}^{T-d} D f(\varepsilon) \mathrm{d} \varepsilon+\int_{T-d}^{+\infty} T f(\varepsilon) \mathrm{d} \varepsilon \\
& =\left(T F(T-d)-\int_{0}^{T-d} F(\varepsilon) \mathrm{d} \varepsilon\right)+(T-T F(T-d))=T-\int_{0}^{T-d} F(\varepsilon) \mathrm{d} \varepsilon
\end{aligned}
$$


TABLE 2. Model notations.

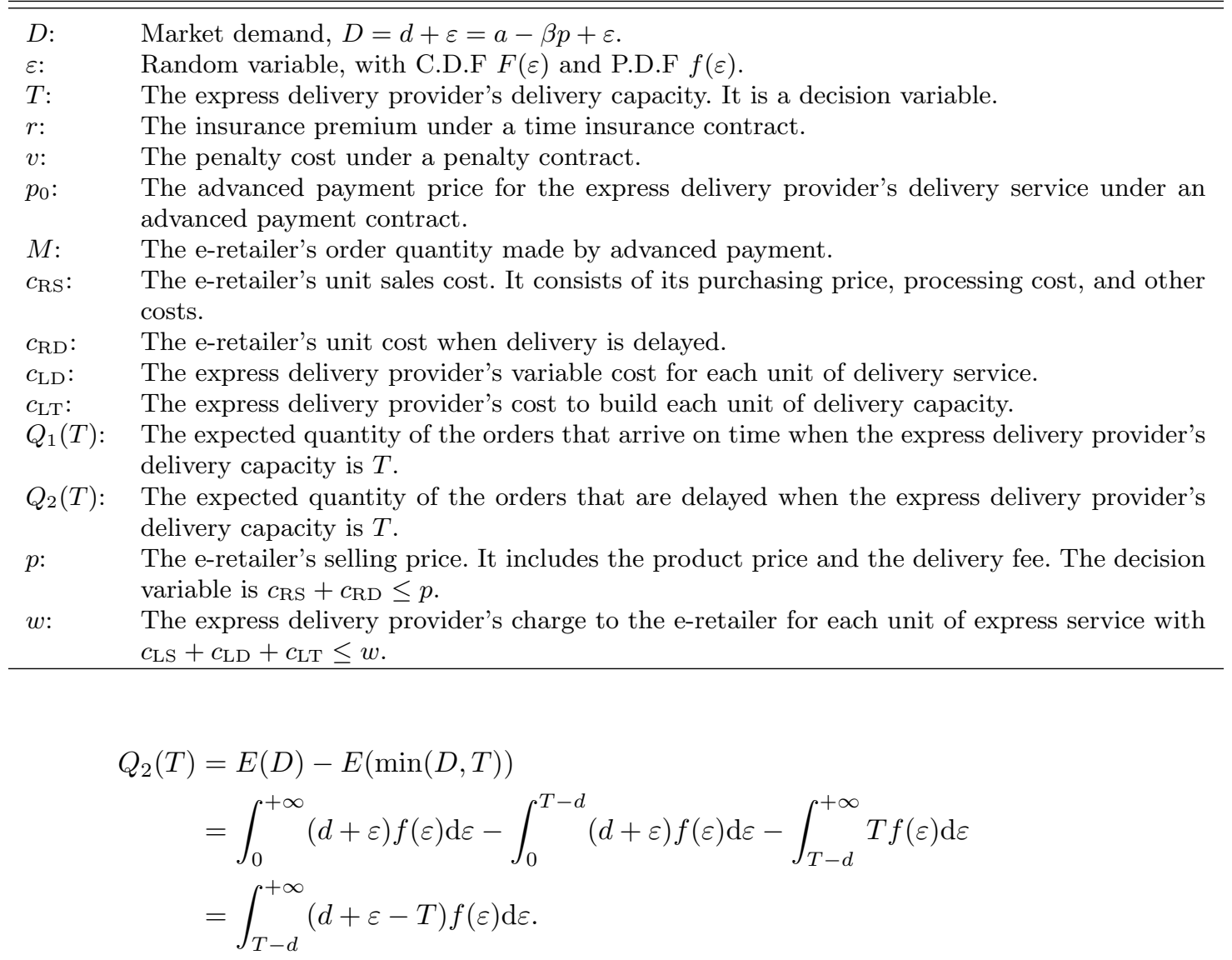

Three contracts with different decision time points are discussed to address the mismatch in demand and supply in the express delivery supply chain: advanced payment contract (ex-ante), penalty contract (ex-post), and the time insurance contract (mixed). This studies analyzed and compared the equilibrium decisions and profits under these three contracts.

In the advance payment contract, the e-retailer can reserve the delivery capacity $M$ from the express delivery provider before demand occurs. The advanced payment contract is implemented before the demand is realized. In the penalty contract, the e-retailer charges the express delivery provider some penalty $v Q_{2}(T)$ for the delayed orders. Thus, the penalty contract is executed after delivery. In the time insurance contract, the e-retailer pays the insurance premium for per unit order before the demand occurs; the delivery is promised within a certain time. If the product is delayed, the express delivery provider returns both the express premium and the insurance premium to the e-retailer. Thus, the time insurance contract is operated at time points both before and after the demand occurs.

Table 2 lists the model notations.

\section{Decentralized MODEL}

In the decentralized model, the express delivery provider and the e-retailer are independent decision makers. The express delivery provider determines its delivery capacity $T$. At the same time, the e-retailer decides its price $p$. The express delivery provider's and the e-retailer's profits are as follows: 


$$
\begin{aligned}
\pi_{R}^{D} & =p E(D)-w E(D)-c_{\mathrm{RS}} E(D)-c_{\mathrm{RD}} Q_{2}(T) \\
& =\left(p-w-c_{\mathrm{RS}}\right) \int_{0}^{+\infty}(d+\varepsilon) f(\varepsilon) \mathrm{d} \varepsilon-c_{\mathrm{RD}} \int_{T-d}^{+\infty}(d+\varepsilon-T) f(\varepsilon) \mathrm{d} \varepsilon . \\
\pi_{L}^{D} & =w E(D)-c_{\mathrm{LS}} E(D)-c_{\mathrm{LD}} Q_{2}(T)-c_{\mathrm{LT}} T \\
& =\left(w-c_{\mathrm{LS}}\right) \int_{0}^{+\infty}(d+\varepsilon) f(\varepsilon) \mathrm{d} \varepsilon-c_{\mathrm{LD}} \int_{T-d}^{+\infty}(d+\varepsilon-T) f(\varepsilon) \mathrm{d} \varepsilon-c_{\mathrm{LT}} T .
\end{aligned}
$$

In equation (4.1), the first term represents the retailer's revenue from the products sold to consumers. The second term represents the retailer's payment for delivering the products. The third term is the retailer's handling cost and the final term is the retailer's loss from a delay.

In equation (4.2), the first term represents the express delivery provider's revenue from delivering all products to consumers. The second term represents the handling cost of the orders. The third term is the loss from delay and the final term is the cost of building the delivery capacity.

In the decentralized model, the express delivery provider sets up its delivery capacity, and the e-retailer simultaneously decides its retail price. Then, random demand is realized. The express delivery provider delivers orders to consumers, using its delivery capacity. Thus, Proposition 4.1 presents the partners' equilibrium solutions in the decentralized model. The proof of Proposition 4.1 is shown in the Appendix A.

Proposition 4.1. In the decentralized case, the express delivery provider's optimal capacity $T^{D^{*}}$ and the eretailer's optimal retail price $p^{D^{*}}$ are expressed as:

$$
\begin{aligned}
p^{D^{*}} & = \begin{cases}\frac{\beta\left(w+c_{\mathrm{RD}}+c_{\mathrm{RS}}\right)+E(\varepsilon)+a}{2 \beta} & \text { if } c_{\mathrm{LD}}<c_{\mathrm{LT}} \\
\frac{\beta\left(w+c_{\mathrm{RS}}+\frac{c_{\mathrm{RD}} c_{\mathrm{LT}}}{c_{\mathrm{LD}}}\right)+E(\varepsilon)+a}{2 \beta} & \text { if } c_{\mathrm{LD}} \geq c_{\mathrm{LT}}\end{cases} \\
T^{D^{*}} & = \begin{cases}0 & \text { if } c_{\mathrm{LD}}<c_{\mathrm{LT}} \\
\bar{F}^{-1}\left(\frac{c_{\mathrm{LT}}}{c_{\mathrm{LD}}}\right)-\frac{\beta\left(w+c_{\mathrm{RS}}+\frac{c_{\mathrm{RD}} c_{\mathrm{LT}}}{c_{\mathrm{LD}}}\right)+E(\varepsilon)-a}{2} & \text { if } c_{\mathrm{LD}} \geq c_{\mathrm{LT}} .\end{cases}
\end{aligned}
$$

Proposition 4.1 shows that, if the express delivery provider experiences a higher cost to build capacity than the cost incurred from delays (i.e., $c_{\mathrm{LD}}<c_{\mathrm{LT}}$ ), it sets $T^{D^{*}}=0$. This leads to a serious express delivery situation where all orders are delayed. The express delivery provider is positively incentivized to build delivery capacity only when $c_{\mathrm{LD}} \geq c_{\mathrm{LT}}$.

\section{Centralized model}

This section considers the centralized case, where the express delivery provider and the e-retailer are integrated as a single company. In this setting, the centralized company sets its price and delivery capacity to maximize the profit presented in equation (5.1).

$$
\begin{aligned}
\pi_{S}^{C} & =\left(p-c_{\mathrm{RS}}-c_{\mathrm{LS}}\right) E(D)-\left(c_{\mathrm{RD}}+c_{\mathrm{LD}}\right) Q_{2}(T)-c_{\mathrm{LT}} T \\
& =\left(p-c_{\mathrm{RS}}-c_{\mathrm{LS}}\right) \int_{0}^{+\infty}(d+\varepsilon) f(\varepsilon) \mathrm{d} \varepsilon-\left(c_{\mathrm{RD}}+c_{\mathrm{LD}}\right) \int_{T-d}^{+\infty}(d+\varepsilon-T) f(\varepsilon) \mathrm{d} \varepsilon-c_{\mathrm{LT}} T .
\end{aligned}
$$

Proposition 5.1 presents the equilibrium solution of the centralized model. The proof of Proposition 5.1 is shown in the Appendix A.

Proposition 5.1. In the centralized case, the express delivery capacity $T^{C^{*}}$ and the retail price $p^{C^{*}}$ are: 
(i)

$$
p^{C^{*}}= \begin{cases}\frac{\beta\left(c_{\mathrm{RD}}+c_{\mathrm{RS}}+c_{\mathrm{LD}}+c_{\mathrm{LS}}\right)+E(\varepsilon)+a}{2 \beta} & \text { if } c_{\mathrm{RD}}+c_{\mathrm{LD}}<c_{\mathrm{LT}} \\ \frac{\beta\left(c_{\mathrm{RS}}+c_{\mathrm{LS}}+c_{\mathrm{LT}}\right)+E(\varepsilon)+a}{2 \beta} & \text { if } c_{\mathrm{RD}}+c_{\mathrm{LD}} \geq c_{\mathrm{LT}}\end{cases}
$$

and

$$
T^{C^{*}}= \begin{cases}0 & \text { if } c_{\mathrm{RD}}+c_{\mathrm{LD}}<c_{\mathrm{LT}} \\ \bar{F}^{-1}\left(\frac{c_{\mathrm{LT}}}{c_{\mathrm{RD}}+c_{\mathrm{LD}}}\right)-\frac{\beta\left(c_{\mathrm{RS}}+c_{\mathrm{LS}}+c_{\mathrm{LT}}\right)+E(\varepsilon)-a}{2} & \text { if } c_{\mathrm{RD}}+c_{\mathrm{LD}} \geq c_{\mathrm{LT}} .\end{cases}
$$

(ii) Comparing the centralized case and the decentralized case, we have:

$$
p^{D^{*}}>p^{C^{*}}, T^{D^{*}} \leq T^{C^{*}}, \pi_{S}^{C}\left(p^{C^{*}}, T^{C^{*}}\right) \geq \pi_{R}^{D}\left(p^{D^{*}}, T^{D^{*}}\right)+\pi_{R}^{D}\left(p^{D^{*}}, T^{D^{*}}\right) .
$$

Proposition 5.1(i) provides the partners' equilibrium solutions in the centralized model. Proposition 5.1(ii) shows that, compared to the decentralized case, the company will build more delivery capacity and charge a lower retail price. As such, the total supply chain profit in the centralized model is no lower than the profit in the decentralized supply chain. The goal of this paper is to identify contracts that improve the performance of the decentralized express delivery supply chain.

\section{Contracts analysis}

Sections 4 and 5 conclude that the total supply chain profit in the centralized model is no lower than the profit in the decentralized supply chain. Thus, this section considers whether the three contracts can increase the profitability of the supply chain, compared to the decentralized case.

\subsection{Advanced payment contract}

In the advanced payment contract, the e-retailer can reserve the delivery capacity from the express delivery provider in advance. Assume that the prepaid price for reserved capacity is $p_{0}$ and the usual price for buying the capacity is $w$. We assume $p_{0} \leq p$ to ensure that both the e-retailer and the express delivery provider are incentivized to join the advanced payment contract. Assume that $M \geq 0$ is the number of early reserved delivery capacities. The express delivery provider accepting the contract must provide sufficient capacity to cover the initial order $M$; otherwise, the provider will incur a large penalty for breaching the contract.

Figure 1 shows the sequence of events in this setting. Before the selling season, based on the prepaid price $p_{0}$, the e-retailer determines the reserved delivery capacities $M$ and sets the product's retail price at $p$. The express delivery provider simultaneously determines delivery capacity. To ensure all the orders are satisfied, we assume that $T \geq M$. After the demand is realized, if the demand exceeds the reserved capacity, the e-retailer pays the extra demand $E\left(D-\min (D, M)^{+}\right)$for the express delivery provider at the standard wholesale price $w$. Then, the e-retailer and express delivery provider receive profit.

The e-retailer's profit is as follows:

$$
\begin{aligned}
\pi_{R}^{E}= & p E(D)-p_{0} M-w E(D-\min (D, M))^{+}-c_{\mathrm{RS}} E(D)-c_{\mathrm{RD}} Q_{2}(T) \\
= & {\left[\left(p-c_{\mathrm{RS}}\right) \int_{0}^{+\infty}(d+\varepsilon) f(\varepsilon) \mathrm{d} \varepsilon-p_{0} M-w \int_{M-d}^{+\infty}(d+\varepsilon-M) f(\varepsilon) \mathrm{d} \varepsilon\right.} \\
& \left.-c_{\mathrm{RD}} \int_{T-d}^{+\infty}(d+\varepsilon-T) f(\varepsilon) \mathrm{d} \varepsilon\right] .
\end{aligned}
$$

In equation (6.1), the first term is the e-retailer's revenue from products sold to consumers. The second term is the e-retailer's prepayment for reserving capacity in the advanced payment contract. The third term is the normal charge for the delivery service, when the e-retailer's early reserved delivery capacity is smaller than demand. The fourth term is the e-retailer's handling cost; the last term is the e-retailer's loss from a delay. 


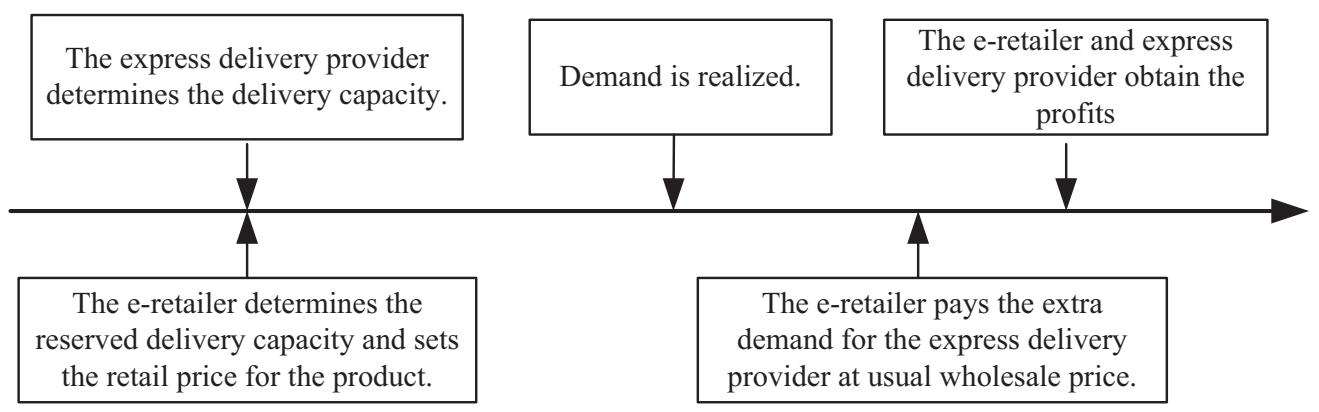

FiguRE 1. Decision sequences under the advanced payment contract.

The express delivery provider's expected profit is:

$$
\begin{aligned}
\pi_{L}^{E}= & p_{0} M+w E(D-\min (D, M))^{+}-c_{\mathrm{LS}} E(D)-c_{\mathrm{LD}} Q_{2}(T)-c_{\mathrm{LT}} T \\
= & {\left[p_{0} M-c_{\mathrm{LS}} \int_{0}^{+\infty}(d+\varepsilon) f(\varepsilon) \mathrm{d} \varepsilon+w \int_{M-d}^{+\infty}(d+\varepsilon-M) f(\varepsilon) \mathrm{d} \varepsilon\right.} \\
& \left.-c_{\mathrm{LD}} \int_{T-d}^{+\infty}(d+\varepsilon-T) f(\varepsilon) \mathrm{d} \varepsilon-c_{\mathrm{LT}} T\right] .
\end{aligned}
$$

In equation (6.2), the express delivery provider obtains revenue $p_{0} M$ from the advanced payment contract and obtains revenue $w E(D=\min (D, M))^{+}$based on the normal charges for the delivery service when the e-retailer's early ordering delivery capacity is smaller than demand. The term $c_{\mathrm{LS}} E D$ is the express delivery provider's cost to deliver the product; the term $c_{\mathrm{LD}} Q_{2}(T)$ represents the cost of delays. The last term is the express delivery provider's cost to build capacity.

The equilibrium solutions are shown in the Table 3, based on the decision sequence in this setting. Next, we discuss how the advanced payment contract coordinates the supply chain. The proofs of the equilibrium solutions and Proposition 6.1 are shown in the Appendix A.

We denote

$$
\begin{aligned}
& \bar{p}_{0}=\left\{p_{0}: \Delta \pi_{R}^{E}\left(p_{0}\right)=\pi_{R}^{E}\left(p^{C^{*}}, T^{C^{*}}\right)-\pi_{R}^{D}\left(p^{D^{*}}, T^{D^{*}}\right)=0\right\} \quad \text { and } \\
& \tilde{p}_{0}=\left\{p_{0}: \Delta \pi_{L}^{E}\left(p_{0}\right)=\pi_{L}^{E}\left(p^{C^{*}}, T^{C^{*}}\right)-\pi_{L}^{D}\left(p^{D^{*}}, T^{D^{*}}\right)=0\right\} .
\end{aligned}
$$

Proposition 6.1. The advanced payment contract can coordinate the express delivery supply chain when $p_{0}^{*}=$ $c_{\mathrm{LS}}+c_{\mathrm{LT}}$. The supply chain partners accept the advanced payment contract if and only if the value of the prepaid price $p_{0}^{*}$ satisfies: $\overline{p_{0}} \geq p_{0}^{*} \geq \max \left(0, \tilde{p_{0}}\right)$.

From Table 3, we can know that the partners have optimal prices $p^{E^{*}}$, the optimal early reserved quantities $M^{E^{*}}$ and the optimal service capacity $T^{E^{*}}$. The supply chain's profit with the advanced payment contract is less than the profit gained in the centralized case. The supply chain's profit with the advanced payment contract is no less than the profit gained in the decentralized case. Comparing the scenarios in terms of profitability, the advanced payment contact is better than the decentralized case and worse than the centralized case. With the advanced payment contract, the e-retailer charges a lower retail price and gains more delivery capacity than the businesses in the decentralized case. However, in this scenario, the e-retailer charges a higher price and receives less delivery capacity than gained in the centralized case. The decentralized supply chain's performance is improved with the advanced payment contract. Thus, Proposition 6.1 shows how the advanced payment contract coordinates the supply chain. Then, we provide the range of $p_{0}$, during which, the e-retailer and delivery service provider can obtain more profits in the advanced payment contract than those in the decentralized case. 


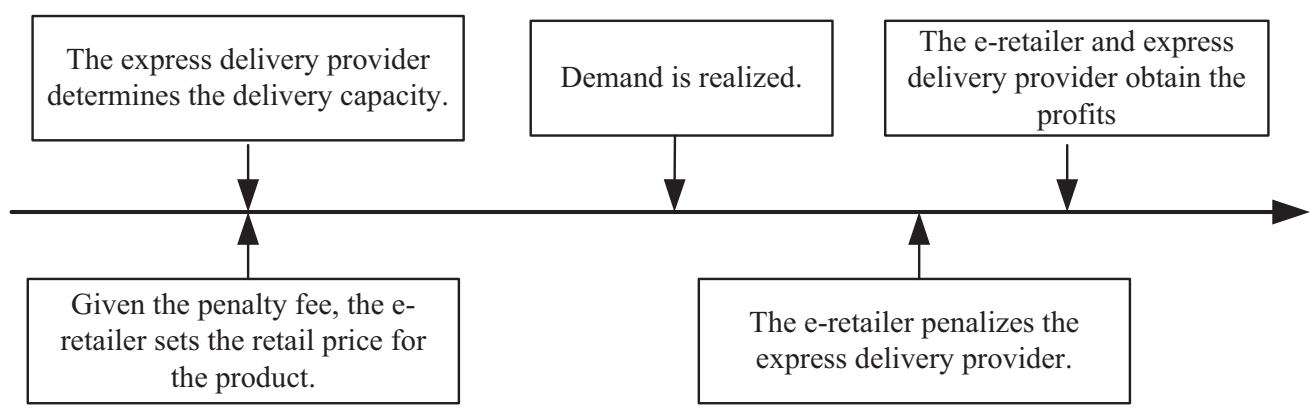

FiguRE 2. Decision sequences under the penalty contract.

\subsection{Penalty contract}

In the penalty contract, when the express delivery provider delays the delivery orders, the e-retailer will penalize the provider for the delayed delivery. Figure 2 shows the decision sequence. Before the selling season, based on the negotiated penalty fee per unit $v$, the e-retailer sets the retail price at $p$ for the product. The express delivery provider simultaneously determines the delivery capacity $T$. The demand is realized and the orders are delivered. The retailer penalizes the express delivery provider the amount of $v Q_{2}(T)$ for any delays. Both firms obtain profits.

The e-retailer's profit is:

$$
\begin{aligned}
\pi_{R}^{P} & =p E(D)-w E(D)-c_{\mathrm{RS}} E(D)-c_{\mathrm{RD}} Q_{2}(T)+v Q_{2}(T) \\
& =\left(p-w-c_{\mathrm{RS}}\right) \int_{0}^{+\infty}(d+\varepsilon) f(\varepsilon) \mathrm{d} \varepsilon-\left(c_{\mathrm{RD}}-v\right) \int_{T-d}^{+\infty}(d+\varepsilon-T) f(\varepsilon) \mathrm{d} \varepsilon
\end{aligned}
$$

In equation (6.3), the first term is the e-retailer's revenue from the products sold to consumers. The second term is the e-retailer's payment for delivering the products. The third term is the e-retailer's handling cost; and the fourth term is the e-retailer's loss from delays. The last term is the penalty for the delay delivery.

The express delivery provider's expected profits are:

$$
\begin{aligned}
\pi_{L}^{P} & =w E(D)-c_{\mathrm{LS}} E(D)-c_{\mathrm{LD}} Q_{2}(T)-v Q_{2}(T)-c_{\mathrm{LT}} T \\
& =\left(w-c_{\mathrm{LS}}\right) \int_{0}^{+\infty}(d+\varepsilon) f(\varepsilon) \mathrm{d} \varepsilon-\left(c_{\mathrm{LD}}+v\right) \int_{T-d}^{+\infty}(d+\varepsilon-T) f(\varepsilon) \mathrm{d} \varepsilon-c_{\mathrm{LT}} T .
\end{aligned}
$$

Equation (6.4) shows that the express delivery provider obtains revenue defined by $w E D$. The term $v Q_{2}(T)$ is the express delivery provider's penalties caused by the delivery delay. The term $c_{\mathrm{LS}} E D$ is the express delivery provider's cost of delivering the product, and the term $c_{\mathrm{LD}} Q_{2}(T)$ is the cost for the delay. The final term is the express delivery provider's cost to build capacity.

The equilibrium solutions are shown in Table 3, based on the decision sequence in this setting. Next, we discuss how the penalty contract coordinates the supply chain. The proofs of the equilibrium solutions and Proposition 6.2 are shown in the Appendix A.

We denote

$$
\begin{aligned}
& v_{0}=\frac{\pi_{R}^{D}\left(p^{D^{*}}, T^{D^{*}}\right)-\left(p^{C^{*}}-w-c_{\mathrm{RS}}\right)\left(d\left(p^{C^{*}}\right)+E(\varepsilon)\right)}{Q_{2}\left(T^{C^{*}}\right)} \\
& v_{1}=\frac{\left(w-c_{\mathrm{LS}}\right)\left(d\left(p^{C^{*}}\right)+E(\varepsilon)\right)-c_{\mathrm{LD}} Q_{2}\left(T^{C^{*}}\right)-c_{\mathrm{LT}} T^{C^{*}}-\pi_{L}^{D}\left(p^{D^{*}}, T^{D^{*}}\right)}{Q_{2}\left(T^{C^{*}}\right)} .
\end{aligned}
$$




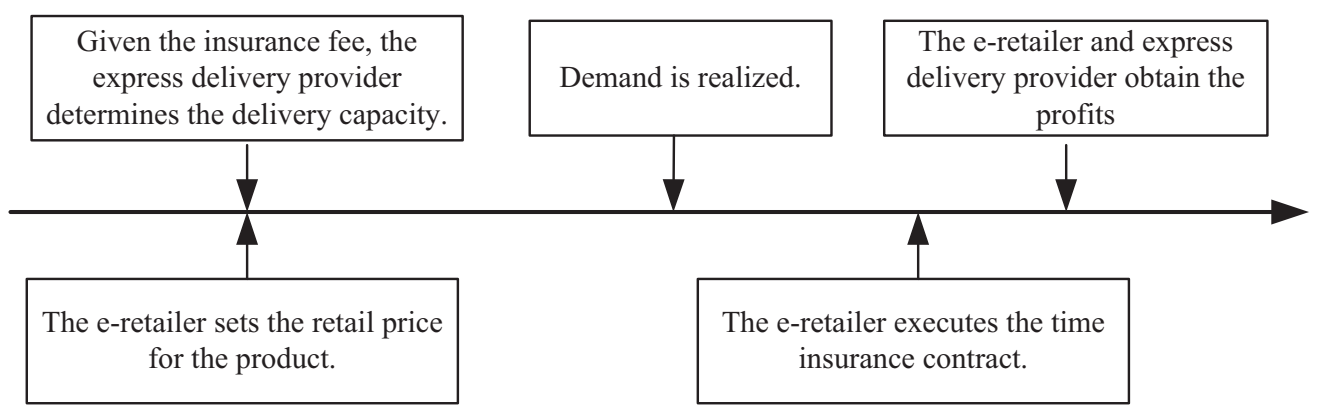

FIGURE 3. Decision sequence with the time insurance contract.

Proposition 6.2. The penalty contract can coordinate the express delivery supply chain system when $v^{*}=$ $\frac{\left(c_{\mathrm{RD}}+c_{\mathrm{LD}}\right) c_{\mathrm{LT}}}{c_{\mathrm{LS}}+2 c_{\mathrm{LT}}-w}-c_{\mathrm{LD}}$. The supply chain partners accept the penalty contract if and only if the value of the penalty fee $v^{*}$ satisfies: $v_{1} \geq v^{*} \geq \max \left(v_{0}, 0\right)$.

Table 3 shows that the retailer and delivery service provider have unique values for the optimal prices $p^{P^{*}}$ and the optimal service capacity $T^{P^{*}}$ to maximize their respective profits. The supply chain's profit with the penalty contract is less than in the centralized case. The supply chain's profit with the penalty contract is no less than in the decentralized case. Proposition 6.2 shows how the penalty contract coordinates the supply chain. Then, we provide the range of $v^{*}$, during which, the e-retailer and delivery service provider can obtain more profits in the penalty contract than those in the decentralized case.

\subsection{Time insurance contract}

The time insurance contract is used by SF-EXPRESS, one of the largest express delivery companies in China, to solve delivery delays during the high-demand selling season. The insurance contract between the e-retailer and the express delivery provider is defined as follows. The e-retailer pays an insurance premium per unit to the express delivery provider; the express delivery provider promises to deliver the product within a certain time; if the product is delayed, the express delivery provider returns the delivery fee and the insurance premium.

Figure 3 shows the decision sequence with the time insurance contract. Before the selling season, based on the negotiated insurance premium per unit $r$, the e-retailer sets the retail price at $p$ for the product. The express delivery provider simultaneously determines the delivery capacity $T$. The demand is realized, and the orders are delivered. Then, the delivery provider returns the delivery fee and the insurance premium for the delayed orders. Both companies obtain profits.

With the time insurance contract, the e-retailer's expected profit is:

$$
\begin{aligned}
\pi_{R}^{T} & =p E(D)-(w+r) E(D)-c_{\mathrm{RS}} E(D)-c_{\mathrm{RD}} Q_{2}(T)+(w+r) Q_{2}(T) \\
& =\left(p-w-r-c_{\mathrm{RS}}\right) \int_{0}^{+\infty}(d+\varepsilon) f(\varepsilon) \mathrm{d} \varepsilon-\left(c_{\mathrm{RD}}-w-r\right) \int_{T-d}^{+\infty}(d+\varepsilon-T) f(\varepsilon) \mathrm{d} \varepsilon .
\end{aligned}
$$

In equation (6.5), the first term is the e-retailer's revenue from the products sold to consumers. The second term is the e-retailer's payment to the delivery provider for delivering the service and insurance premium. The third term is the e-retailer's handling cost; and the fourth term is the e-retailer's loss from delay. The final term is the express delivery provider's penalty resulting from delayed deliveries. 
The express delivery provider's expected profit is:

$$
\begin{aligned}
\pi_{L}^{T} & =(w+r) E(D)-c_{\mathrm{LS}} E(D)-\left(c_{\mathrm{LD}}+w+r\right) Q_{2}(T)-c_{\mathrm{LT}} T \\
& =\left(w-c_{\mathrm{LS}}+r\right) \int_{0}^{+\infty}(d+\varepsilon) f(\varepsilon) \mathrm{d} \varepsilon-\left(c_{\mathrm{LD}}+w+r\right) \int_{T-d}^{+\infty}(d+\varepsilon-T) f(\varepsilon) \mathrm{d} \varepsilon-c_{\mathrm{LT}} T .
\end{aligned}
$$

In equation (6.6), the express delivery provider obtains revenue $(w+r) E D$ from the delivery service and insurance premium; the term $c_{\mathrm{LS}} E D$ is the express delivery provider's cost of delivering the product; and the term $\left(c_{\mathrm{LD}}+w+r\right) Q_{2}(T)$ is the loss from the cost of delay. The final term is the express delivery provider's cost to build capacity.

The equilibrium solutions are shown in Table 3, based on the decision sequence in this setting. Next, we discuss how the time insurance contract coordinates the supply chain. The proofs of the equilibrium solutions and Proposition 6.3 are shown in the Appendix A.

First, we denote

$$
r_{0}=\frac{\left(c_{\mathrm{LD}}^{2}+c_{\mathrm{LD}} w-c_{\mathrm{LT}} c_{\mathrm{RD}}-c_{\mathrm{LT}} c_{\mathrm{LD}}\right)+\sqrt{\left(c_{\mathrm{LD}}^{2}+c_{\mathrm{LD}} w-c_{\mathrm{LT}} c_{\mathrm{RD}}-c_{\mathrm{LT}} c_{\mathrm{LD}}\right)^{2}+4 c_{\mathrm{LD}} c_{\mathrm{LT}} w\left(c_{\mathrm{RD}}+c_{\mathrm{LD}}\right)}}{2 c_{\mathrm{LD}}} .
$$

Then, we have

$$
p^{D^{*}}=p^{T^{*}} \Leftrightarrow c_{\mathrm{LD}} r_{0}^{2}+\left(c_{\mathrm{LD}}\left(c_{\mathrm{LD}}+w\right)-c_{\mathrm{LT}}\left(c_{\mathrm{RD}}+c_{\mathrm{LD}}\right)\right) r_{0}-w c_{\mathrm{LT}}\left(c_{\mathrm{RD}}+c_{\mathrm{LD}}\right)=0 .
$$

We denote

$$
\begin{aligned}
& \bar{r}_{0}=\frac{\left(p^{C^{*}}-w-c_{\mathrm{RS}}\right)\left(d\left(p^{C^{*}}\right)+E(\varepsilon)\right)+w Q_{2}\left(T^{C^{*}}\right)-\pi_{R}^{D}\left(p^{D^{*}}, T^{D^{*}}\right)}{d\left(p^{C^{*}}\right)+E(\varepsilon)-Q_{2}\left(T^{C^{*}}\right)} \text { and } \\
& \bar{r}_{1}=\frac{\pi_{L}^{D}\left(p^{D^{*}}, T^{D^{*}}\right)-\left(w-c_{\mathrm{LS}}\right)\left(d\left(p^{C^{*}}\right)+E(\varepsilon)\right)+\left(c_{\mathrm{LD}}+w\right) Q_{2}\left(T^{C^{*}}\right)+c_{\mathrm{LT}} T^{C^{*}}}{d\left(p^{C^{*}}\right)+E(\varepsilon)-Q_{2}\left(T^{C^{*}}\right)} .
\end{aligned}
$$

Proposition 6.3. The time insurance contract can coordinate express delivery supply chain system when $r^{*}=\frac{\left(2 c_{\mathrm{LT}}+c_{\mathrm{LS}}-c_{\mathrm{LD}}-2 w\right)+\sqrt{\left(2 c_{\mathrm{LT}}+c_{\mathrm{LS}}-c_{\mathrm{LD}}-2 w\right)^{2}+4\left(\left(c_{\mathrm{LT}}+c_{\mathrm{LS}}\right)\left(c_{\mathrm{LD}}+w\right)-c_{\mathrm{RD}} c_{\mathrm{LT}}\right)}}{2}$ The supply chain partners accept the time insurance contract if and only if the value of the insurance fee $r^{*}$ satisfies: $\bar{r}_{0} \geq r^{*} \geq \max \left(\bar{r}_{1}, 0\right)$.

Table 3 shows that the retailer and delivery service provider have equilibrium solutions $p^{T^{*}}$ and $T^{T^{*}}$, respectively. The supply chain's profit with the time insurance contract in the decentralized case is less than the profit realized in the centralized case. When the cost of holding delivery capacity is relatively large $\left(c_{I D}<c_{\mathrm{LT}} \leq c_{\mathrm{LD}}+w+r\right)$, the time insurance contract outperforms the decentralized model. When $c_{\mathrm{LT}} \leq c_{\mathrm{LD}}$, the time insurance contract outperforms the decentralized model when the insurance premium is $r \in\left[0, r_{0}\right]$. Proposition 6.3 shows how the time insurance contract coordinates the supply chain. Then, we provide the range of $r^{*}$, during which, the e-retailer and delivery service provider can obtain more profits in the time insurance contract than those in the decentralized case.

We denote $r_{1}=\frac{\sqrt{c_{\mathrm{LT}} \beta+c_{\mathrm{LT}} \sqrt{\beta^{2}+8 \beta\left(c_{\mathrm{RD}}+c_{\mathrm{LD}}\right)}}}{2}-c_{\mathrm{LD}}-w$. Then, we have $\partial T^{T^{*}} / \partial r=2\left(\left(c_{\mathrm{LD}}+w+r_{1}\right)^{2}\right)^{2}-$ $c_{\mathrm{LT}} \beta\left(c_{\mathrm{LD}}+w+r_{1}\right)^{2}-c_{\mathrm{LT}}^{2} \beta\left(c_{\mathrm{LD}}+c_{\mathrm{RD}}\right)=0$.

\section{SENSITIVITy ANALYSIS}

Based on some of the equilibrium solutions in the previous section of this paper, we have performed some sensitivity analysis on some parameters. 
Corollary 7.1. The influences of the e-retailer's and express delivery provider's per unit cost of delay on the solutions and profits are:

$$
\frac{\partial p^{D^{*}}}{\partial c_{\mathrm{RD}}}>0, \frac{\partial T^{D^{*}}}{\partial c_{\mathrm{LD}}}>0, \frac{\partial \pi_{R}^{D}}{\partial c_{\mathrm{RD}}} \leq 0, \quad \text { and } \quad \frac{\partial \pi_{L}^{D}}{\partial c_{\mathrm{LD}}} \leq 0
$$

Based on Corollary 7.1, we know that the e-retailer's selling price and the express delivery capacity are positively related to the per unit cost of delay; however, the profits are negatively related to the per unit cost of delay.

Corollary 7.2. The influences of the e-retailer's and express delivery provider's per unit cost of delay on solutions and profits are:

$$
\frac{\partial p^{C^{*}}}{\partial c_{\mathrm{RD}}} \geq 0, \frac{\partial T^{C^{*}}}{\partial c_{\mathrm{LD}}}>0, \frac{\partial \pi_{S}^{C}}{\partial c_{\mathrm{RD}}} \leq 0, \quad \text { and } \quad \frac{\partial \pi_{S}^{D}}{\partial c_{\mathrm{LD}}} \leq 0
$$

Corollary 7.2 demonstrates that the e-retailer's selling price and the express delivery provider's capacity are both positively related to their per unit cost of delay; however, their profits are negatively related to the per unit cost of delay. When the cost of delay is large, the e-retailer raises the retail price to reduce market demand. In addition, the express delivery provider builds a large capacity, to alleviate the mismatch between capacity supply and market demand.

Corollary 7.3. The influences of the per unit cost of delay and advanced payment price on the partners' solutions and profits are:

$$
\frac{\partial p^{E^{*}}}{\partial p_{0}} \geq 0, \frac{\partial T^{E^{*}}}{\partial p_{0}} \leq 0, \frac{\partial M^{E^{*}}}{\partial p_{0}} \leq 0, \frac{\partial T^{E^{*}}}{\partial c_{\mathrm{LD}}}>0, \frac{\partial \pi_{R}^{E}}{\partial c_{\mathrm{RD}}} \leq 0, \quad \text { and } \quad \frac{\partial \pi_{L}^{E}}{\partial c_{\mathrm{LD}}} \leq 0 .
$$

Corollary 7.3 indicates that the equilibrium retail price increases the $p_{0}$. This indicates that if the prepaid price of reserved capacity is high, the e-retailer will charge the consumers higher retail prices. We also find that the equilibrium delivery capacity and early reserving delivery capacity can decrease the $p_{0}$. If the express delivery provider charges a high price for reserving capacity, the e-retailer will reserve smaller amounts of capacity. The result is that the express delivery provider may build less delivery capacity. In addition, we find that the express delivery capacity is positively related to the unit cost of delay; however, they experience opposite profits. That is, when the cost of delay is high, the express delivery provider will build a larger delivery capacity to meet demand.

Corollary 7.4. The influences of the e-retailer's and express delivery provider's per unit cost of delay on the partners' solutions and profits are:

$$
\frac{\partial p^{p^{*}}}{\partial c_{\mathrm{RD}}}>0, \frac{\partial T^{p^{*}}}{\partial c_{\mathrm{LD}}} \geq 0, \frac{\partial p^{p^{*}}}{\partial v}<0, \frac{\partial T^{p^{*}}}{\partial v} \geq 0, \frac{\partial \pi_{R}^{P}}{\partial c_{\mathrm{RD}}} \leq 0, \quad \text { and } \quad \frac{\partial \pi_{L}^{P}}{\partial c_{\mathrm{LD}}} \leq 0 .
$$

Corollary 7.4 indicates that the e-retailer's selling price and the express delivery capacity are not negatively related to their per unit cost of delay. The e-retailer's retail price decreases with the penalty fee, while the express delivery provider's capacity increases with the penalty fee. The partners' profits decrease as the per unit cost of delay increases. As the penalty fee increases, the e-retailer can reduce the retail price to increase demand; correspondingly, the express delivery provider can offer more delivery capacity to meet the demand created by the reduced retail price. 


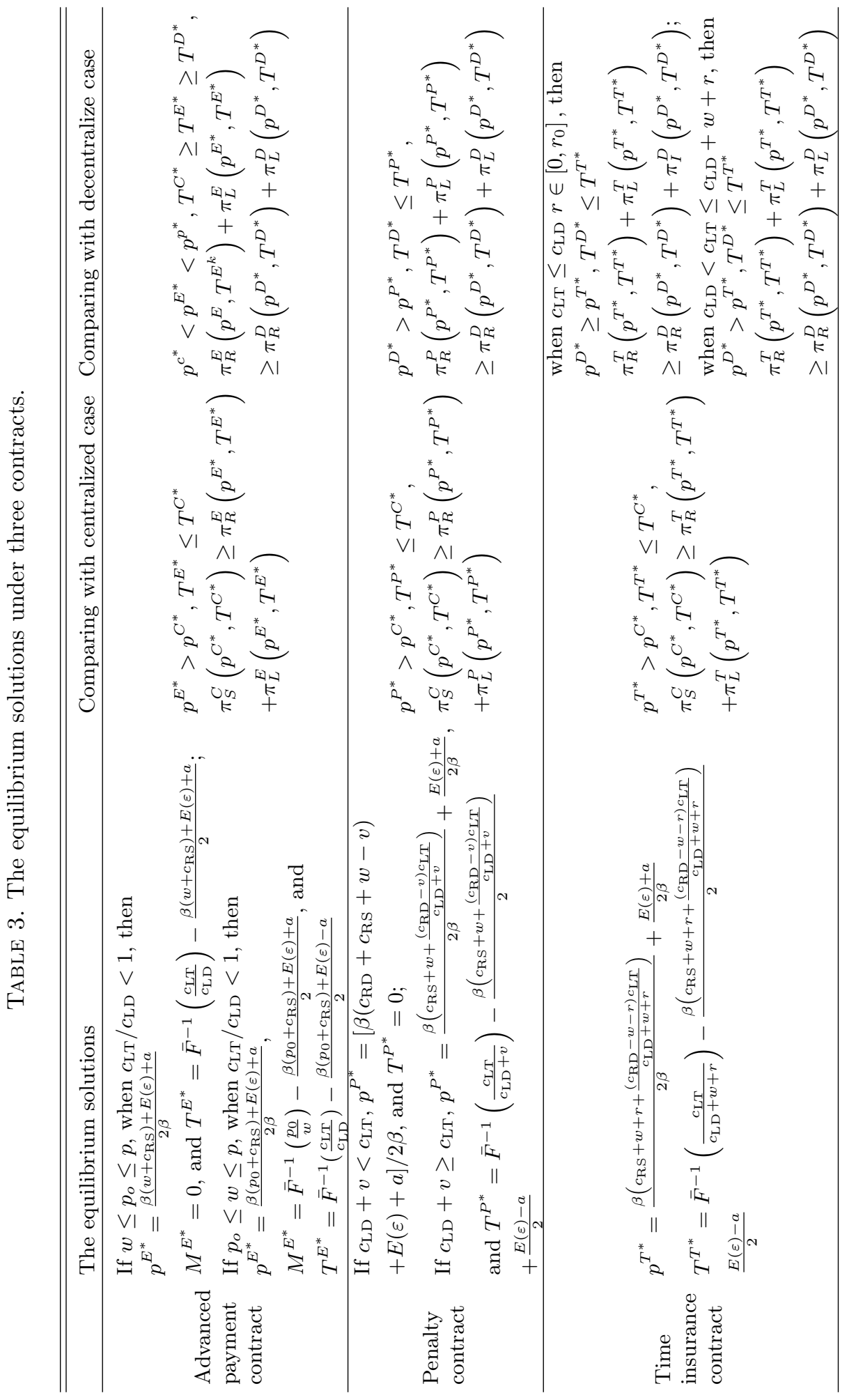


Corollary 7.5. The influences of the per unit cost of delay and the insurance premium on the partners' solutions and profits are:

$$
\frac{\partial p^{T^{*}}}{\partial c_{\mathrm{RD}}}>0, \frac{\partial T^{T^{*}}}{\partial c_{\mathrm{LD}}}>0, \frac{\partial \pi_{R}^{T}}{\partial c_{\mathrm{RD}}} \leq 0, \quad \text { and } \quad \frac{\partial \pi_{L}^{T}}{\partial c_{\mathrm{LD}}} \leq 0
$$

If $r \in\left[0, \max \left(0, \sqrt{\left(c_{\mathrm{LD}}+c_{\mathrm{RD}}\right) c_{\mathrm{LT}}}-c_{\mathrm{LD}}-w\right)\right], \partial p^{T^{*}} / \partial r \leq 0$;

If $r \in\left(\max \left(0, \sqrt{\left(c_{\mathrm{LD}}+c_{\mathrm{RD}}\right) c_{\mathrm{LT}}}-c_{\mathrm{LD}}-w\right), p^{T^{*}}\right]$, then $\partial p^{T^{*}} / \partial r>0$;

If $r \in\left[0, r_{1}\right)$, we have $\partial T^{T^{*}} / \partial r<0$; If $r \in\left[r_{1}, p^{T^{*}}\right]$, then $\partial T^{T^{*}} / \partial r \geq 0$.

Corollary 7.5 indicates that the e-retailer's selling price and the express delivery provider's capacity increase along with per unit cost of delay. Their profits decrease along with their unit cost of delay. If the insurance premium is relatively small, the e-retailer's price and express delivery provider's capacity decrease with the insurance premium. If the insurance premium is relatively large, the e-retailer's price and the express delivery provider's capacity increase along with the insurance premium.

\section{Contracts COMPARISON}

Based on model analysis in Section 6 , when $c_{\mathrm{LT}} \leq c_{\mathrm{LD}}$, supply chain partners have equilibrium solutions under three contracts: the advanced payment contract, the penalty contract, and the time insurance contract. In this section, we investigate which contract is better for the supply chain partners when the three contracts can coordinate the supply chain. This results in Propositions 8.1 and 8.2. The proof of Propositions 8.1 and 8.2 are shown in the Appendix A.

Proposition 8.1. When the three contracts can coordinate the supply chain, we can investigate which contract is better for the e-retailer:

(i) If $\left(w-p_{0}^{*}\right) M^{E^{*}}-w \int_{0}^{M^{E^{*}}-d\left(p^{C^{*}}\right)} F(\varepsilon) \mathrm{d} \varepsilon-v^{*} Q_{2}\left(T^{C^{*}}\right) \geq c_{\mathrm{RD}} Q_{2}\left(T^{C^{*}}\right)$, then $\pi_{R}^{E} \geq \pi_{R}^{P}$;

$$
\text { if }\left(w-p_{0}^{*}\right) M^{E^{*}}-w \int_{0}^{M^{E^{*}}-d\left(p^{C^{*}}\right)} F(\varepsilon) \mathrm{d} \varepsilon-v^{*} Q_{2}\left(T^{C^{*}}\right)<c_{\mathrm{RD}} Q_{2}\left(T^{C^{*}}\right) \text {, then } \pi_{R}^{E}<\pi_{R}^{P} \text {. }
$$

(ii) If $r^{*}\left(d\left(p^{C^{*}}\right)+E(\varepsilon)-Q_{2}\left(T^{C^{*}}\right)\right)+v^{*} Q_{2}\left(T^{C^{*}}\right) \geq w Q_{2}\left(T^{C^{*}}\right)$, then $\pi_{R}^{P} \geq \pi_{R}^{T}$; if $r^{*}\left(d\left(p^{C^{*}}\right)+E(\varepsilon)-Q_{2}\left(T^{C^{*}}\right)\right)+v^{*} Q_{2}\left(T^{C^{*}}\right)<w Q_{2}\left(T^{C^{*}}\right)$, then $\pi_{R}^{P}<\pi_{R}^{T}$.

(iii) If $c_{\mathrm{RD}} Q_{2}\left(T^{C^{*}}\right) \geq r^{*}\left(d\left(p^{C^{*}}\right)+E(\varepsilon)-Q_{2}\left(T^{C^{*}}\right)\right)+\left(w-p_{0}^{*}\right) M^{E^{*}}-w \int_{0}^{M^{E^{*}}-d\left(p^{C^{*}}\right)}$ $F(\varepsilon) \mathrm{d} \varepsilon-w Q_{2}\left(T^{C^{*}}\right)$, then $\pi_{R}^{T} \geq \pi_{R}^{R} ;$

if $c_{\mathrm{RD}} Q_{2}\left(T^{C^{*}}\right)<r^{*}\left(d\left(p^{C^{*}}\right)+E(\varepsilon)-Q_{2}\left(T^{C^{*}}\right)\right)+\left(w-p_{0}^{*}\right) M^{E^{*}}-w \int_{0}^{M^{E^{*}}-d\left(p^{C^{*}}\right)} F(\varepsilon) \mathrm{d} \varepsilon-w Q_{2}\left(T^{C^{*}}\right)$, then $\pi_{R}^{T}<\pi_{R}^{R}$.

From e-retailer perspective, Proposition 8.1(i) indicate the e-retailer prefers advanced payment contract to penalty contract when its unit cost of delayed orders is lower. The lower delayed cost may not stimulate the service provider to improve its delivery capacity. The e-retailers prefers to penalty contract when its unit cost of delayed orders is high. Proposition 8.1(ii) indicates the e-retailer prefers penalty contract to time insurance contract when the wholesale price is lower and prefers time insurance contract when the wholesale price is high. Proposition 8.1(iii) indicates the e-retailer prefer the time insurance contract to the advanced payment contract when its unit cost of delayed orders is high. The e-retailer prefers advanced payment contract to time insurance contract when its unit cost of delayed orders is lower.

Thus, based on Proposition 8.1, we can obtain that when its unit cost of delayed orders is lower, the eretailer will choose the advance payment contract among three contracts. When its unit cost of delayed orders is medium, the e-retailer will opt for the time insurance contract. When its unit cost of delayed orders is high, 
the e-retailer will not choose the advanced payment contract. In this case, whether the e-retailer chooses the time insurance contract and penalty contract depends on the value of wholesale price.

Proposition 8.2. When the three contracts can coordinate the supply chain, we can investigate which contract is better for the provider:

(i) If $v^{*} Q_{2}\left(T^{C^{*}}\right)+p_{0}^{*} M^{E^{*}} \geq w M^{E^{*}}+w \int_{0}^{M^{E^{*}}-d\left(p^{C^{*}}\right)} F(\varepsilon) \mathrm{d} \varepsilon$, then $\pi_{L}^{E} \geq \pi_{L}^{P}$.

$$
\text { If } v^{*} Q_{2}\left(T^{C^{*}}\right)+p_{0}^{*} M^{E^{*}}<w M^{E^{*}}+w \int_{0}^{M^{E^{*}}-d\left(p^{C^{*}}\right)} F(\varepsilon) \mathrm{d} \varepsilon \text {, then } \pi_{L}^{E}<\pi_{L}^{P} \text {. }
$$

(ii) If $w Q_{2}\left(T^{C^{*}}\right) \geq r^{*}\left(d\left(p^{C^{*}}\right)+E(\varepsilon)-Q_{2}\left(T^{C^{*}}\right)\right)+v^{*} Q_{2}\left(T^{C^{*}}\right)$, then $\pi_{L}^{P} \geq \pi_{L}^{T}$. If $w Q_{2}\left(T^{C^{*}}\right)<r^{*}\left(d\left(p^{C^{*}}\right)+E(\varepsilon)-Q_{2}\left(T^{C^{*}}\right)\right)+v^{*} Q_{2}\left(T^{C^{*}}\right)$, then $\pi_{L}^{P}<\pi_{L}^{T}$.

(iii) If $r^{*}\left(d\left(p^{C^{*}}\right)+E(\varepsilon)-Q_{2}\left(T^{C^{*}}\right)\right)+\left(w-p_{0}^{*}\right) M^{E^{*}} \geq w Q_{2}\left(T^{C^{*}}\right)-w \int_{0}^{M^{E^{*}}-d\left(p^{C^{*}}\right)} F(\varepsilon) \mathrm{d} \varepsilon$, then $\pi_{L}^{T} \geq \pi_{L}^{E}$. If $r^{*}\left(d\left(p^{C^{*}}\right)+E(\varepsilon)-Q_{2}\left(T^{C^{*}}\right)\right)+\left(w-p_{0}^{*}\right) M^{E^{*}}<w Q_{2}\left(T^{C^{*}}\right)-w \int_{0}^{M^{E^{*}}-d\left(p^{C^{*}}\right)} F(\varepsilon) \mathrm{d} \varepsilon$, then $\pi_{L}^{T}<\pi_{L}^{E}$.

Proposition 8.2(i) indicates the delivery service provider prefers advanced payment contract to penalty contract when wholesale price is lower. And the provider prefers penalty contract to advanced payment contract when the wholesale price is high. Proposition 8.2(ii) indicates the provider prefers penalty contract to the time insurance contract when the wholesale price is high and prefers to time insurance contract when the wholesale price is lower. Proposition 8.2(iii) indicates whether the provider choose time insurance contract or advanced payment contract depends on the wholesale price, delayed orders and reserved delivery capacity.

Thus, based on Proposition 8.2, we can obtain that when the wholesale price is lower, the provider will not choose the penalty contract among the three contracts. When the wholesale price is medium, the provider will opt for the advanced payment contract. When the wholesale price is high, the provider is willing to choose the penalty contract.

\section{NUMERICAL ANALYSIS}

Given that the analytical expressions might be too complex to understand meaningful insights, in this section, we carry out extensive numerical experiments to illustrate the equilibrium decisions under different models and contracts. We then discuss the effects of unit cost of delayed orders $\left(c_{\mathrm{RD}}, c_{\mathrm{LD}}\right)$ and contract parameters on the equilibrium decision solutions and the profits of the retailer and delivery provider.

\subsection{Numerical analysis of profits}

In this section, we carry out numerical experiments to compare the profits of both e-retailer and delivery provider under advanced payment contract, penalty contract, and time insurance contract. The numerical values of the parameters used in the experiments are given by the following:

$$
a=15, \beta=0.6, \varepsilon \sim E(2), c_{\mathrm{LD}}=2 .
$$

Form Figures 4 and 5, we can obtain that when its unit cost of delayed orders is lower, the e-retailer will choose the advance payment contract among three contracts. When its unit cost of delayed orders is medium, the e-retailer will opt for the time insurance contract. When its unit cost of delayed orders is high, the e-retailer will choose the penalty contract. Meanwhile, we can find by comparing Figures 4 and 5 that the time insurance contract has an advantage over penalty contract for e-retailer under unit high cost of delayed orders scene and high wholesale price. Otherwise there is no advantage .

Form Figure 6, we can obtain when the wholesale price is lower, the provider will choose the time insurance contract among the three contracts. When the wholesale price is medium, the provider will opt for the advanced payment contract. When the wholesale price is high, the provider is willing to choose the penalty contract. 


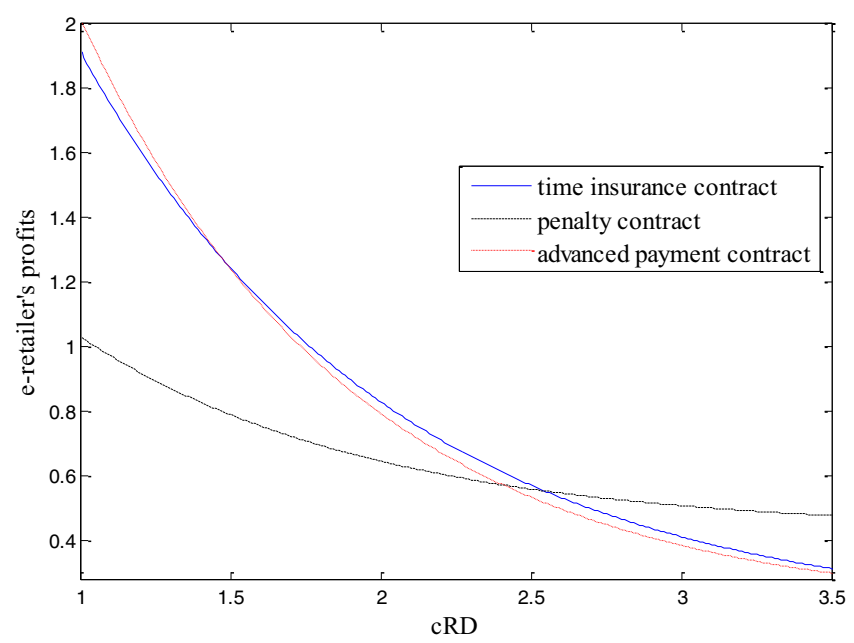

Figure 4 . The effect of unit cost of delayed orders $\left(c_{\mathrm{RD}}\right)$ on e-retailer's profits $(w=5)$.

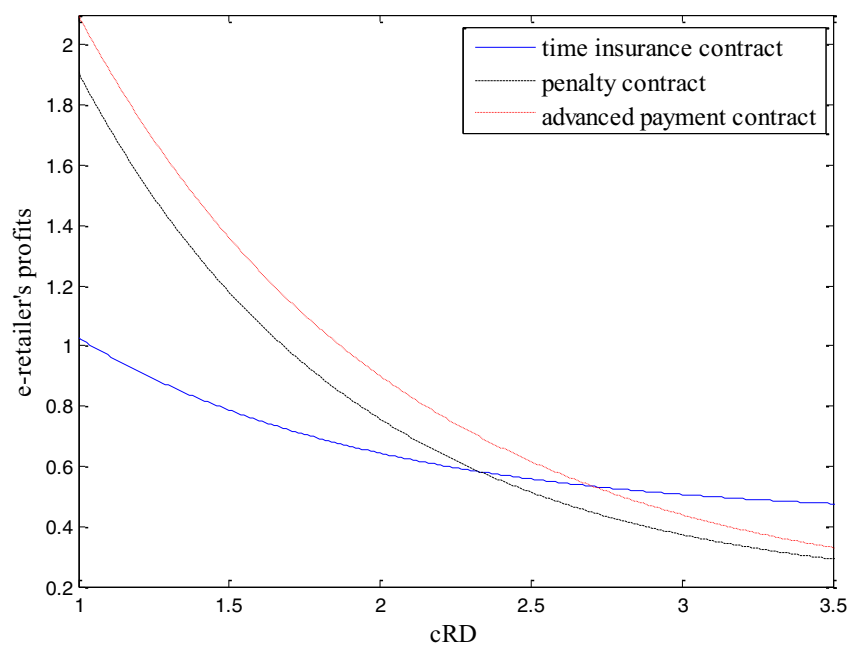

Figure 5 . The effect of unit cost of delayed orders $\left(c_{\mathrm{RD}}\right)$ on e-retailer's profits $(w=10)$.

\subsection{Numerical analysis of pricing and capacity}

In this section, we carry out numerical experiments to the change of the pricing and capacity under advanced payment contract, penalty contract, and time insurance contract and two model. The numerical values of the parameters used in the experiments are given by the following:

$$
a=15, \beta=0.6, \varepsilon \sim E(2), w=5 .
$$

Form Figures 7 and 8, we can get that the e-retailer's selling price and the express delivery capacity are positively related to the per unit cost of delay $\left(c_{\mathrm{RD}}, c_{\mathrm{LD}}\right)$ under advanced payment contract, penalty contract, and time insurance contract and two decentralized and centralized model. 


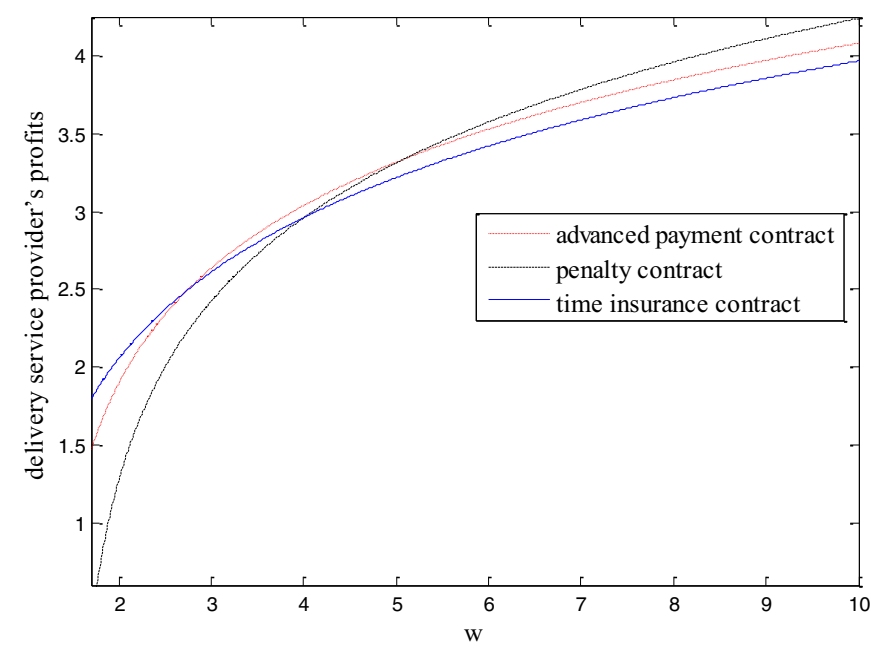

Figure 6 . The effect of wholesale price $(w)$ on the delivery service provider's profits.

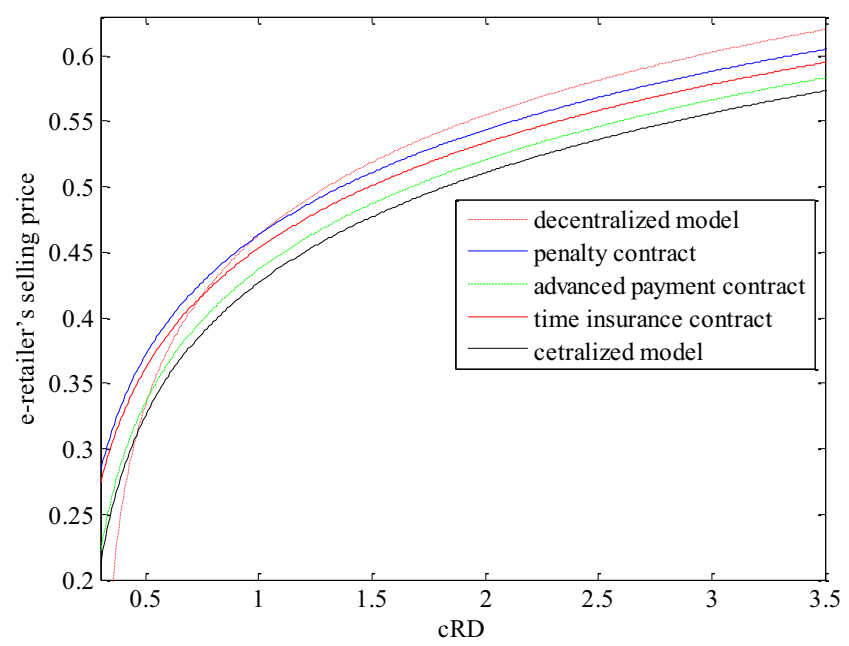

FIgURE 7 . The effect of unit cost of delayed orders $\left(c_{\mathrm{LD}}\right)$ on e-retailer's selling price.

Form Figure 9, we can get that the equilibrium retail price increases along with the advanced payment price $\left(p_{0}\right)$. We also find that the equilibrium delivery capacity and early reserving delivery capacity can decrease along with the advanced payment price $\left(p_{0}\right)$.

Form Figure 10, we can obtain that the e-retailer's retail price decreases with the penalty fee, while the express delivery provider's capacity increases with the penalty fee $(v)$. And form Figure 11, we can obtain that the e-retailer's price and express delivery provider's capacity first increases and then decreases with the insurance premium $(r)$.

\section{MANAGERIAL INSIGHTS}

The innovation and novelty of our research comes from real business practice cases and previous studies. The theoretical results of our research should be returned to practical business practice to guide business practice. 


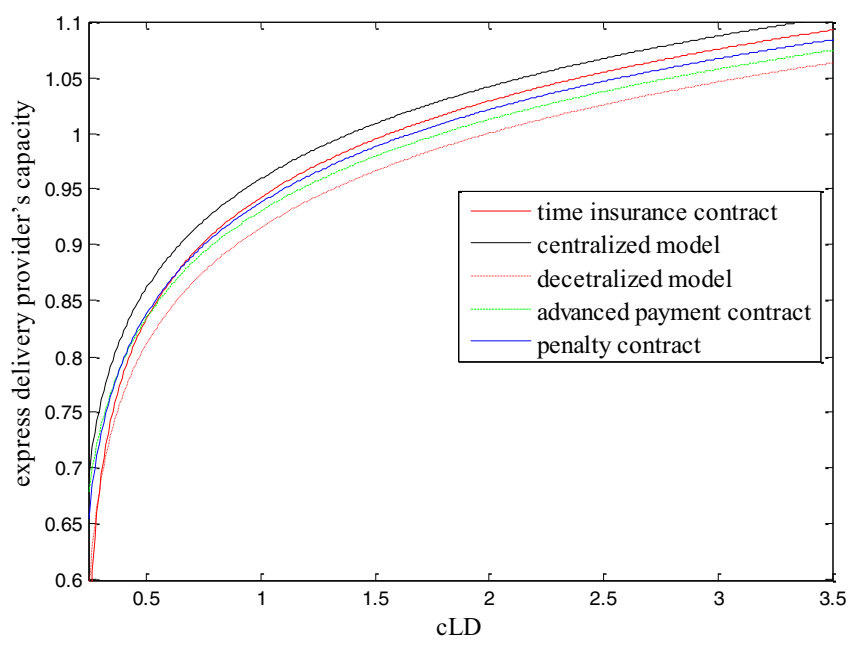

Figure 8 . The effect of unit cost of delayed orders $\left(c_{\mathrm{LD}}\right)$ on delivery capacity.

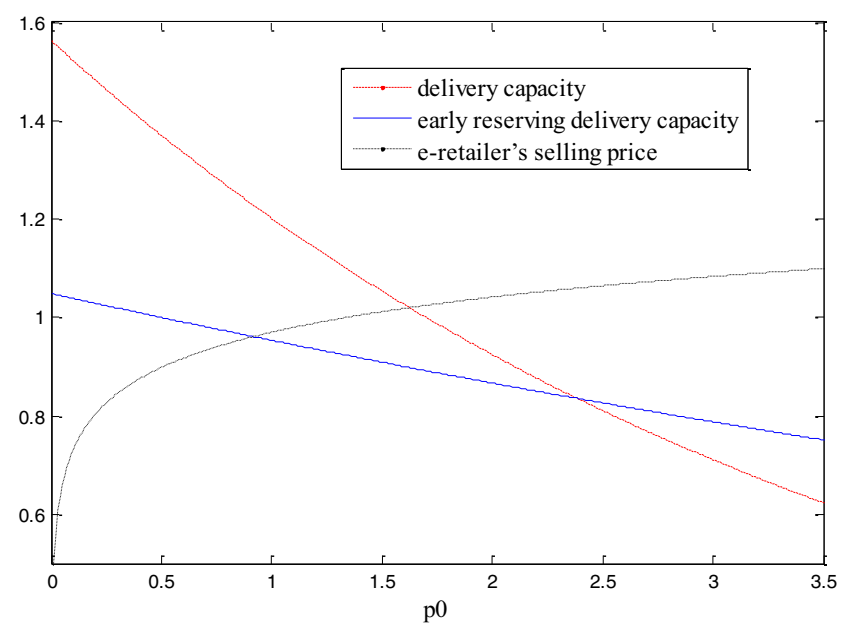

FIGURE 9 . The effect of advanced payment price $\left(p_{0}\right)$ on delivery capacity, reserving delivery capacity and e-retailer's selling price under advanced payment contract.

Therefore, the theoretical results obtained from the research are divided into two parts. The more important part is the management insight, and the theoretical contribution, research insufficiency and future research are put in the conclusion section.

We found that when its unit cost of delayed orders is lower, the e-retailer will choose the advance payment contract among three contracts. When its unit cost of delayed orders is medium, the e-retailer will opt for the time insurance contract. When its unit cost of delayed orders is high, the e-retailer will not choose the advanced payment contract. For T-mall retailers of Alibaba, we consider that different retailers have different unit cost of delayed orders in reality, so the choice of each retailer is also different. Therefore, they can measure their unit cost of delayed orders, and then make the best decision for themselves, so that their profits can be guaranteed.

For the express service provider, whether they choose the time insurance contract and penalty contract depends on the value of wholesale price. We can obtain that when the wholesale price is lower, the provider will 


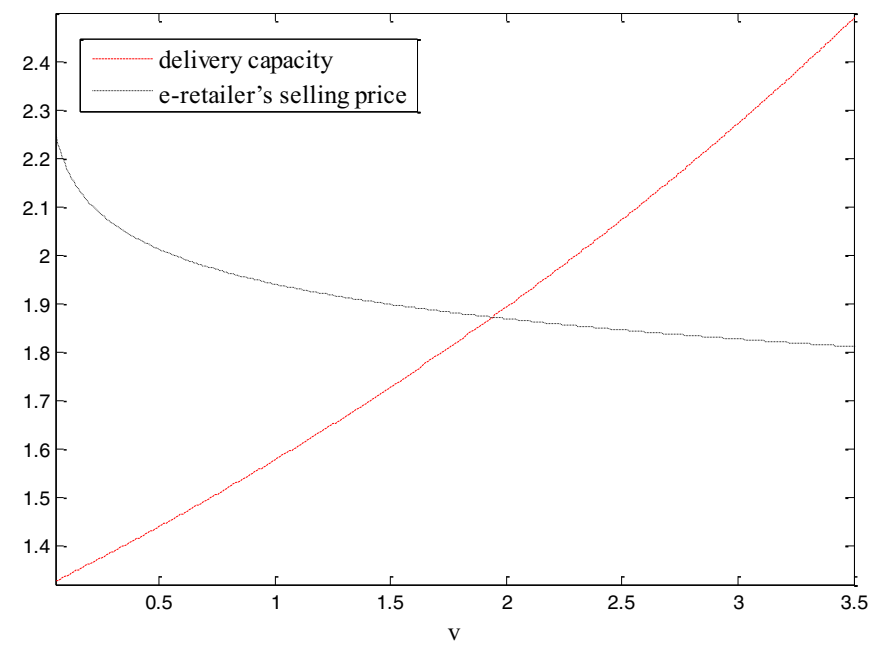

Figure 10. The effect of penalty fee $(v)$ on delivery capacity, $r$ and e-retailer's selling price under penalty contract.

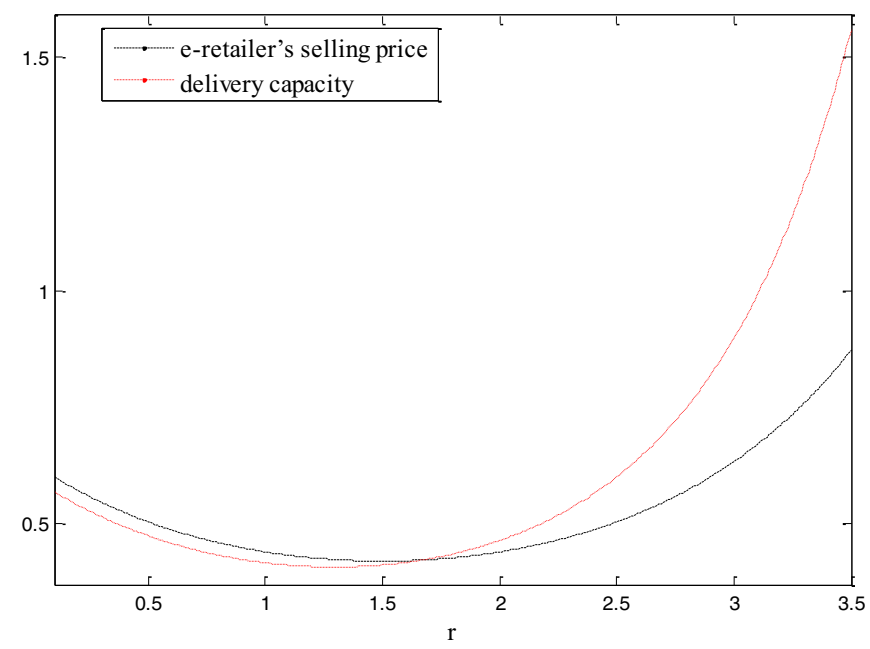

FIGURE 11. The effect of insurance premium $(r)$ on delivery capacity, rand e-retailer's selling price under time insurance contract.

not choose the penalty contract. When the wholesale price is medium, the provider will opt for the advanced payment contract. When the wholesale price is high, the provider is willing to choose the penalty contract. For $\mathrm{SF}$ - the express service provider, the wholesale price is the main source of their profits, so the wholesale price greatly affects their choice of contracts. At the same time, wholesale prices also have a great impact on the quality of service. 


\section{Conclusions}

This paper investigated the e-retailer's pricing and the express delivery provider's capacity strategies for the express delivery supply chain under three contracts: advanced payment contract, penalty contract, and the time insurance contract. The equilibrium solutions in the express delivery supply chain under three contracts are shown in Table 3. Based on the equilibrium solutions, we have discussed how the three contracts coordinate the supply chain. Next, we have investigated which contract is better for the supply chain partners when the three contracts can coordinate the supply chain. In the context of capacity strategy and price strategy, we theoretically analyzed the coordination effect of three contracts on service supply chain, which enriched the previous research results. Meanwhile, we introduce the insurance contract into the service supply chain, which makes up the gap of the insurance contract in the service supply chain research field.

Limitations and possible future research related to this study are as follows. First, in this paper, one important assumption is that information about demand is shared between the e-retailer and express delivery provider. In reality, the e-retailer may have more information about the demand than the express delivery provider. Thus, future studies should consider demand forecasting between the e-retailer and the express delivery provider. Second, this study considered a supply chain consisting of one e-retailer and one express delivery provider. In reality, there may be several express delivery providers to provide services for the e-retailers. Thus, future studies should consider competition in the express delivery supply chain. Finally, another interesting research project would be to investigate other contracts to coordinate the express delivery supply chain.

Acknowledgements. We thank Prof. Ridha Mahjoub, Editor-in-Chief and two anonymous reviewers for their comments on earlier versions of this paper.

\section{Appendix A.}

Proof of Proposition 4.1. Based on the benchmark decentralized model:

$$
\left\{\begin{array}{l}
\pi_{R}^{D}=\left(p-w-c_{\mathrm{RS}}\right) \int_{0}^{+\infty}(d+\varepsilon) f(\varepsilon) \mathrm{d} \varepsilon-c_{\mathrm{RD}} \int_{T-d}^{+\infty}(d+\varepsilon-T) f(\varepsilon) \mathrm{d} \varepsilon \\
\pi_{L}^{D}=\left(w-c_{\mathrm{LS}}\right) \int_{0}^{+\infty}(d+\varepsilon) f(\varepsilon) \mathrm{d} \varepsilon-c_{\mathrm{LD}} \int_{T-d}^{+\infty}(d+\varepsilon-T) f(\varepsilon) \mathrm{d} \varepsilon-c_{\mathrm{LT}} T .
\end{array}\right.
$$

The second derivatives of the profits with respect to price and service capacity are:

$$
\left\{\begin{array}{l}
\frac{\partial^{2} \pi_{R}^{D}}{\partial p^{2}}=-2 \beta-c_{\mathrm{RD}} \beta^{2} f(T-d)<0 \\
\frac{\partial^{2} \pi_{L}^{D}}{\partial T^{2}}=-c_{\mathrm{LD}} f(T-d)<0 .
\end{array}\right.
$$

Thus, the retailer's and express delivery provider's profits are concave with the retail prices and service capacity. The optimal strategies are $\left(p^{D^{*}}, T^{D^{*}}\right)$.

Based on $\left\{\begin{array}{l}\frac{\partial \pi_{R}^{D}}{\partial p_{D}}=0 \\ \frac{\partial \pi_{L}^{D}}{\partial T}=0\end{array}\right.$, we obtain:

$$
\begin{aligned}
p^{D^{*}} & = \begin{cases}\frac{\beta\left(w+c_{\mathrm{RD}}+c_{\mathrm{RS}}\right)+E(\varepsilon)+a}{2 \beta} & \text { if } c_{\mathrm{LD}}<c_{\mathrm{LT}} \\
\frac{\beta\left(w+c_{\mathrm{RS}}+\frac{c_{\mathrm{RD}} c_{\mathrm{LT}}}{c_{\mathrm{LD}}}\right)+E(\varepsilon)+a}{2 \beta} & \text { if } c_{\mathrm{LD}} \geq c_{\mathrm{LT}}\end{cases} \\
T^{D^{*}} & = \begin{cases}0 & \text { if } c_{\mathrm{LD}}<c_{\mathrm{LT}} \\
\bar{F}^{-1}\left(\frac{c_{\mathrm{LT}}}{c_{\mathrm{LD}}}\right)-\frac{\beta\left(w+c_{\mathrm{RS}}+\frac{c_{\mathrm{RD}} c_{\mathrm{LT}}}{c_{\mathrm{LD}}}\right)+E(\varepsilon)-a}{2} & \text { if } c_{\mathrm{LD}} \geq c_{\mathrm{LT}} .\end{cases}
\end{aligned}
$$

Proof of Corollary 7.1. The proof is straightforward and is omitted here. 
Proof of Proposition 5.1. (i) Based on the centralized model, we have:

$$
\begin{aligned}
\pi_{S}^{C} & =\left(p-c_{\mathrm{RS}}-c_{\mathrm{LS}}\right) E D-\left(c_{\mathrm{RD}}+c_{\mathrm{LD}}\right) Q_{2}(T)-c_{\mathrm{LT}} T \\
& =\left(p-c_{\mathrm{RS}}-c_{\mathrm{LS}}\right) \int_{0}^{+\infty}(d+\varepsilon) f(\varepsilon) \mathrm{d} \varepsilon-\left(c_{\mathrm{RD}}+c_{\mathrm{LD}}\right) \int_{T-d}^{+\infty}(d+\varepsilon-T) f(\varepsilon) \mathrm{d} \varepsilon-c_{\mathrm{LT}} T .
\end{aligned}
$$

The Hessian Matrix of the supply chain's profits is assumed to be a negative definite matrix as follows:

$$
H=\left[\begin{array}{ll}
\frac{\partial^{2} \pi_{S}^{C}}{\partial p^{2}} & \frac{\partial^{2} \pi_{S}^{C}}{\partial p \partial T} \\
\frac{\partial^{2} \pi_{S}^{C}}{\partial T \partial p} & \frac{\partial^{2} \pi_{S}^{C}}{\partial T^{2}}
\end{array}\right]
$$

Because $\pi_{S}^{C}\left(p^{C}, T^{C}\right)$ is jointly concave in $\left(p^{C}, T^{C}\right)$, and an optimal solution to the optimization problem $\max \left(p^{C}, T^{C}\right)$ exists, then:

$$
\begin{aligned}
p^{C^{*}} & = \begin{cases}\frac{\beta\left(c_{\mathrm{RD}}+c_{\mathrm{RS}}+c_{\mathrm{LD}}+c_{\mathrm{LS}}\right)+E(\varepsilon)+a}{2 \beta} & \text { if } c_{\mathrm{RD}}+c_{\mathrm{LD}}<c_{\mathrm{LT}} \\
\frac{\beta\left(c_{\mathrm{RS}}+c_{\mathrm{LS}}+c_{\mathrm{LT}}\right)+E(\varepsilon)+a}{2 \beta} & \text { if } c_{\mathrm{RD}}+c_{\mathrm{LD}} \geq c_{\mathrm{LT}}\end{cases} \\
T^{C^{*}} & = \begin{cases}0 & \text { if } c_{\mathrm{RD}}+c_{\mathrm{LD}}<c_{\mathrm{LT}} \\
\bar{F}^{-1}\left(\frac{c_{\mathrm{LT}}}{c_{\mathrm{RD}}+c_{\mathrm{LD}}}\right)-\frac{\beta\left(c_{\mathrm{RS}}+c_{\mathrm{LS}}+c_{\mathrm{LT}}\right)+E(\varepsilon)-a}{2} & \text { if } c_{\mathrm{RD}}+c_{\mathrm{LD}} \geq c_{\mathrm{LT}} .\end{cases}
\end{aligned}
$$

(ii) Comparing the centralized case and the decentralized case yields:

$$
\begin{aligned}
p^{D^{*}}-p^{C^{*}} & = \begin{cases}\frac{c_{\mathrm{RD}}+w-c_{\mathrm{LS}}-c_{\mathrm{LT}}}{2}>0 & \text { if } c_{\mathrm{LD}}<c_{\mathrm{LT}} \leq c_{\mathrm{RD}}+c_{\mathrm{LD}} \\
\frac{w-c_{\mathrm{LS}}-c_{\mathrm{LT}}+\frac{c_{\mathrm{RD}} c_{\mathrm{LT}}}{c_{\mathrm{LD}}}>0}{2} & \text { if } c_{\mathrm{LT}}<c_{\mathrm{LD}}\end{cases} \\
T^{D^{*}}-T^{C^{*}} & = \begin{cases}-\bar{F}^{-1}\left(\frac{c_{\mathrm{LT}}}{c_{\mathrm{RD}}+c_{\mathrm{LD}}}\right)+\frac{\beta\left(c_{\mathrm{RS}}+c_{\mathrm{LS}}+c_{\mathrm{LT}}\right)+E(\varepsilon)-a}{2}<0 & \text { if } c_{\mathrm{LD}}<c_{\mathrm{LT}} \leq c_{\mathrm{RD}}+c_{\mathrm{LD}} \\
\bar{F}^{-1}\left(\frac{c_{\mathrm{LT}}}{c_{\mathrm{LD}}}\right)-\bar{F}^{-1}\left(\frac{c_{\mathrm{LT}}}{c_{\mathrm{RD}}+c_{\mathrm{LD}}}\right)-\frac{w-c_{\mathrm{LS}}-c_{\mathrm{LT}}+\frac{c_{\mathrm{RD}} c_{\mathrm{LT}}}{c_{\mathrm{LD}}}}{2}<0 & \text { if } c_{\mathrm{LT}}<c_{\mathrm{LD}} .\end{cases}
\end{aligned}
$$

We conclude that $p^{D^{*}}>p^{C^{*}}, T^{D^{*}} \leq T^{C^{*}}$. Because $\pi_{S}^{C}\left(p^{C}, T^{C}\right)$ is jointly concave in $\left(p^{C}, T^{C}\right)$, and there is unique optimal $\left(p^{C^{*}}, T^{C^{*}}\right)$, then $\pi_{S}^{C}\left(p^{C^{*}}, T^{C^{*}}\right) \geq \pi_{R}^{D}\left(p^{D^{*}}, T^{D^{*}}\right)+\pi_{R}^{D}\left(p^{D^{*}}, T^{D^{*}}\right)$.

Proof of Corollary 7.2. The proof is straightforward and is omitted here.

Proof of Proposition 6.1. (i) Based on the advanced payment contract:

$$
\begin{aligned}
\pi_{L}^{E}= & p_{0} M+\left(w-c_{\mathrm{LS}}\right) \int_{0}^{+\infty}(d+\varepsilon) f(\varepsilon) \mathrm{d} \varepsilon-w\left(M-\int_{0}^{M-d} F(\varepsilon) \mathrm{d} \varepsilon\right) \\
& -c_{\mathrm{LD}} \int_{T-d}^{+\infty}(d+\varepsilon-T) f(\varepsilon) \mathrm{d} \varepsilon-c_{\mathrm{LT}} T .
\end{aligned}
$$

The second derivatives of the profits with respect to service capacity is assumed to be as follows: $\frac{\partial^{2} \pi_{L}^{E}}{\partial T^{2}}=$ $-c_{\mathrm{LD}} f(T-d)<0$. Assuming $\frac{\partial \pi_{L}^{E}}{\partial T}=0$, we obtain

$$
T^{E^{*}}=\bar{F}^{-1}\left(\frac{c_{\mathrm{LT}}}{c_{\mathrm{LD}}}\right)+d .
$$

From

$$
\pi_{R}^{E}=\left(p-w-c_{\mathrm{RS}}\right) \int_{0}^{+\infty}(d+\varepsilon) f(\varepsilon) \mathrm{d} \varepsilon-p_{0} M+w\left(M-\int_{0}^{M-d} F(\varepsilon) \mathrm{d} \varepsilon\right)-c_{\mathrm{RD}} \int_{T-d}^{+\infty}(d+\varepsilon-T) f(\varepsilon) \mathrm{d} \varepsilon
$$


the Hessian Matrix of the retailer's profits is assumed to be a negative definite matrix as follows:

$$
H=\left[\begin{array}{ll}
\frac{\partial^{2} \pi_{R}^{E}}{\partial p^{2}} & \frac{\partial^{2} \pi_{R}^{E}}{\partial p \partial M} \\
\frac{\partial^{2} \pi_{R}^{E}}{\partial M \partial p} & \frac{\partial^{2} \pi_{R}^{E}}{\partial M^{2}}
\end{array}\right]
$$

because $\pi_{R}^{E}\left(p^{E}, T^{E}\right)$ is jointly concave in $\left(p^{E}, T^{E}\right)$ and an optimal solution to the optimization problem $\max \pi_{R}^{E}\left(p^{E}, T^{E}\right)$ exists.

Based on $\left\{\begin{array}{l}\frac{\partial \pi_{R}^{E}}{\partial p^{E}}=0 \\ \frac{\partial \pi_{R}^{E}}{\partial M}=0\end{array}\right.$, we obtain

$$
\left\{\begin{array}{l}
p^{E^{*}}=\frac{\beta\left(p_{0}+c_{\mathrm{RS}}\right)+E(\varepsilon)+a}{2 \beta} \\
M^{E^{*}}=\bar{F}^{-1}\left(\frac{p_{0}}{w}\right)-\frac{\beta\left(p_{0}+c_{\mathrm{RS}}\right)+E(\varepsilon)-a}{2} \\
T^{E^{*}}=\bar{F}^{-1}\left(\frac{c_{\mathrm{LT}}}{c_{\mathrm{LD}}}\right)+d^{*} .
\end{array}\right.
$$

This analysis yields the following conclusions.

If $w \leq p_{0} \leq p$, when $\frac{c_{\mathrm{LT}}}{c_{\mathrm{LD}}}<1$, then $\frac{\partial \pi_{R}^{E}}{\partial M}<0$ and

$$
\left\{\begin{array}{l}
p^{E^{*}}=\frac{\beta\left(w+c_{\mathrm{RS}}\right)+E(\varepsilon)+a}{2 \beta} \\
M^{E^{*}}=0 \\
T^{E^{*}}=\bar{F}^{-1}\left(\frac{c_{\mathrm{LT}}}{c_{\mathrm{LD}}}\right)-\frac{\beta\left(w+c_{\mathrm{RS}}\right)+E(\varepsilon)-a}{2} .
\end{array}\right.
$$

If $p_{o} \leq w \leq p$, when $\frac{c_{\mathrm{LT}}}{c_{\mathrm{LD}}}<1$, then

$$
\left\{\begin{array}{l}
p^{E^{*}}=\frac{\beta\left(p_{0}+c_{\mathrm{RS}}\right)+E(\varepsilon)+a}{2 \beta} \\
M^{E^{*}}=\bar{F}^{-1}\left(\frac{p_{0}}{w}\right)-\frac{\beta\left(p_{0}+c_{\mathrm{RS}}\right)+E(\varepsilon)-a}{2} \\
T^{E^{*}}=\bar{F}^{-1}\left(\frac{c_{\mathrm{LT}}}{c_{\mathrm{LD}}}\right)-\frac{\beta\left(p_{0}+c_{\mathrm{RS}}\right)+E(\varepsilon)-a}{2} .
\end{array}\right.
$$

(ii) When comparing the centralized case and the advanced payment contract, we have the following:

If $w \leq p_{o} \leq p$, when $c_{\mathrm{LT}} \leq c_{\mathrm{LD}}$, then:

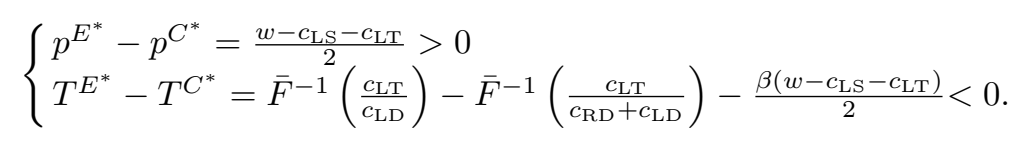

If $p_{o} \leq w \leq p$, when $c_{\mathrm{LT}} \leq c_{\mathrm{LD}}$, then:

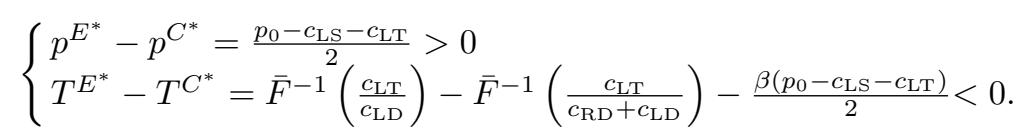

$\pi_{S}^{C}\left(p^{C}, T^{C}\right)$ is jointly concave in $\left(p^{C}, T^{C}\right)$. There is a unique optimal $\left(p^{C^{*}}, T^{C^{*}}\right)$, which yields $\pi_{S}^{C}\left(p^{C^{*}}, T^{C^{*}}\right) \geq \pi_{R}^{E}\left(p^{E^{*}}, T^{E^{*}}\right)+\pi_{R}^{E}\left(p^{E^{*}}, T^{E^{*}}\right)$.

(iii) When comparing the decentralized case and the advanced payment contract, we have:

If $w \leq p_{o} \leq p$, then

$$
\left\{\begin{array}{l}
p^{E^{*}}-p^{D^{*}}=\frac{-c_{\mathrm{RD}}}{2}<0 \\
T^{E^{*}}-T^{D^{*}}=\frac{\beta c_{R D}}{2}>0
\end{array}\right.
$$


If $p_{o} \leq w \leq p$, then

$$
\left\{\begin{array}{l}
p^{E^{*}}-p^{D^{*}}=\frac{p_{0}-w-c_{\mathrm{RD}}}{2}<0 \\
T^{E^{*}-T^{D^{*}}=\frac{\beta\left(w-p_{0}+c_{\mathrm{RD}}\right)}{2}>0}
\end{array}\right.
$$

because $\pi_{S}^{C}\left(p^{C}, T^{C}\right)$ is jointly concave in $\left(p^{C}, T^{C}\right)$. There is a unique optimal $\left(p^{C^{*}}, T^{C^{*}}\right)$, which yields $p^{C^{*}}<p^{E^{*}}<p^{D^{*}}, T^{C^{*}} \geq T^{E^{*}} \geq T^{D^{*}}$,

$$
\left\{\begin{array}{l}
\pi_{S}^{C}\left(p^{C^{*}}, T^{C^{*}}\right)>\pi_{S}^{C}\left(p^{E^{*}}, T^{C^{*}}\right)>\pi_{S}^{C}\left(p^{D^{*}}, T^{C^{*}}\right) \\
\pi_{S}^{C}\left(p^{C^{*}}, T^{C^{*}}\right)>\pi_{S}^{C}\left(p^{C^{*}}, T^{E^{*}}\right)>\pi_{S}^{C}\left(p^{C^{*}}, T^{D^{*}}\right) \\
\pi_{S}^{C}\left(p^{C^{*}}, T^{C^{*}}\right) \geq \pi_{S}^{C}\left(p^{E^{*}}, T^{E^{*}}\right)>\pi_{S}^{C}\left(p^{E^{*}}, T^{D^{*}}\right)>\pi_{S}^{C}\left(p^{D^{*}}, T^{D^{*}}\right) \\
\pi_{S}^{C}\left(p^{E^{*}}, T^{E^{*}}\right)=\pi_{R}^{E}\left(p^{E^{*}}, T^{E^{*}}\right)+\pi_{L}^{E}\left(p^{E^{*}}, T^{E^{*}}\right) \\
>\pi_{S}^{C}\left(p^{D^{*}}, T^{D^{*}}\right)=\pi_{R}^{D}\left(p^{D^{*}}, T^{D^{*}}\right)+\pi_{L}^{D}\left(p^{D^{*}}, T^{D^{*}}\right) .
\end{array}\right.
$$

(iv)

$$
\begin{aligned}
\Delta \pi_{R}^{E}= & \pi_{R}^{E}\left(p^{C^{*}}, T^{C^{*}}\right)-\pi_{R}^{D}\left(p^{D^{*}}, T^{D^{*}}\right)=\left[\left(p^{C^{*}}-c_{\mathrm{RS}}-w\right)\left(d\left(p^{C^{*}}\right)+E(\varepsilon)\right)\right. \\
& \left.-\left(p_{0}-w\right) M^{E^{*}}-w \int_{0}^{M^{E^{*}}-d\left(p^{C^{*}}\right)} F(\varepsilon) \mathrm{d} \varepsilon-c_{\mathrm{RD}} Q_{2}\left(T^{C^{*}}\right)-\pi_{R}^{D}\left(p^{D^{*}}, T^{D^{*}}\right)\right] .
\end{aligned}
$$

We denote $\bar{p}_{0}=\left\{p_{0}: \Delta \pi_{R}^{E}\left(p_{0}\right)=\pi_{R}^{E}\left(p^{C^{*}}, T^{C^{*}}\right)-\pi_{R}^{D}\left(p^{D^{*}}, T^{D^{*}}\right)=0\right\}$. When $\overline{p_{0}} \geq p_{0}$, we have $\Delta \pi_{R}^{E} \geq 0$.

$$
\begin{aligned}
\Delta \pi_{L}^{E}= & \pi_{L}^{E}\left(p^{C^{*}}, T^{C^{*}}\right)-\pi_{L}^{D}\left(p^{D^{*}}, T^{D^{*}}\right)=\left[\left(w-c_{\mathrm{LS}}\right)\left(d\left(p^{C^{*}}\right)+E(\varepsilon)\right)-w M^{E^{*}}\right. \\
& \left.+p_{0} M^{E^{*}}-w \int_{0}^{M^{E^{*}}-d\left(p^{C^{*}}\right)} F(\varepsilon) \mathrm{d} \varepsilon-c_{\mathrm{LD}} Q_{2}\left(T^{C^{*}}\right)-c_{\mathrm{LT}} T^{C^{*}}-\pi_{L}^{D}\left(p^{D^{*}}, T^{D^{*}}\right)\right] .
\end{aligned}
$$

We denote $\tilde{p}_{0}=\left\{p_{0}: \Delta \pi_{L}^{E}\left(p_{0}\right)=\pi_{L}^{E}\left(p^{C^{*}}, T^{C^{*}}\right)-\pi_{L}^{D}\left(p^{D^{*}}, T^{D^{*}}\right)=0\right\}$. When $\overline{p_{0}} \leq p_{0}$, we have $\Delta \pi_{L}^{E} \geq 0$.

Proof of Corollary 7.3. The proof is straightforward and is omitted here.

Proof of Proposition 6.2. (i) Based on the penalty contract:

$$
\left\{\begin{array}{l}
\pi_{R}^{P}=\left(p-w-c_{\mathrm{RS}}\right) \int_{0}^{+\infty}(d+\varepsilon) f(\varepsilon) \mathrm{d} \varepsilon-\left(c_{\mathrm{RD}}-v\right) \int_{T-d}^{+\infty}(d+\varepsilon-T) f(\varepsilon) \mathrm{d} \varepsilon \\
\pi_{L}^{P}=\left(w-c_{\mathrm{LS}}\right) \int_{0}^{+\infty}(d+\varepsilon) f(\varepsilon) \mathrm{d} \varepsilon-\left(c_{\mathrm{LD}}+v\right) \int_{T-d}^{+\infty}(d+\varepsilon-T) f(\varepsilon) \mathrm{d} \varepsilon-c_{\mathrm{LT}} T .
\end{array}\right.
$$

The second derivatives of the profits with respect to the price and service capacity are assumed to be as follows:

$$
\left\{\begin{array}{l}
\frac{\partial^{2} \pi_{R}^{P}}{\partial p^{2}}=-2 \beta-\left(c_{\mathrm{RD}}-v\right) \beta^{2} f(T-d)<0 \\
\frac{\partial^{2} \pi_{L}^{P}}{\partial T^{2}}=-\left(c_{\mathrm{LD}}+v\right) f(T-d)<0
\end{array}\right.
$$

Thus, the retailer's and express provider's profits are concave with the retail prices and service capacity. The optimal strategies are $\left(p^{P^{*}}, T^{P^{*}}\right)$. 
Based on $\left\{\begin{array}{l}\frac{\partial \pi_{R}^{P}}{\partial p}=0 \\ \frac{\partial \pi_{L}^{P}}{\partial T}=0\end{array}\right.$, we can obtain:

$$
\begin{aligned}
p^{P^{*}} & = \begin{cases}\frac{\beta\left(c_{\mathrm{RD}}+c_{\mathrm{RS}}+w-v\right)+E(\varepsilon)+a}{2 \beta} & \text { if } c_{\mathrm{LD}}+v<c_{\mathrm{LT}} \\
\frac{\beta\left(c_{\mathrm{RS}}+w+\frac{\left(c_{\mathrm{RD}}-v\right) c_{\mathrm{LT}}}{c_{\mathrm{LD}}+v}\right)+E(\varepsilon)+a}{2 \beta} & \text { if } c_{\mathrm{LD}}+v \geq c_{\mathrm{LT}}\end{cases} \\
T^{P^{*}} & = \begin{cases}0 & \text { if } c_{\mathrm{LD}}+v<c_{\mathrm{LT}} \\
\bar{F}^{-1}\left(\frac{c_{\mathrm{LT}}}{c_{\mathrm{LD}}+v}\right)-\frac{\beta\left(c_{\mathrm{RS}}+w+\frac{\left(c_{\mathrm{RD}}-v\right) c_{\mathrm{LT}}}{c_{\mathrm{LD}}+v}\right)+E(\varepsilon)-a}{2} & \text { if } c_{\mathrm{LD}}+v \geq c_{\mathrm{LT}} .\end{cases}
\end{aligned}
$$

(ii) Comparing the centralized case and the penalty contract yields:

$$
\begin{aligned}
& p^{P^{*}}-p^{C^{*}}= \begin{cases}\frac{c_{\mathrm{RD}}+w-c_{\mathrm{LT}}-c_{\mathrm{LS}}-v}{2}>0 & \text { if } c_{\mathrm{LD}}+v \leq c_{\mathrm{LT}}<c_{\mathrm{LD}}+c_{\mathrm{RD}} \\
\frac{w-c_{\mathrm{LT}}-c_{\mathrm{LS}}+\frac{\left(c_{\mathrm{RD}}-v\right) c_{\mathrm{LT}}}{c_{\mathrm{RD}}+v}}{2}>0 & \text { if } c_{\mathrm{LT}}<c_{\mathrm{LD}}+v\end{cases} \\
& T^{P^{*}}-T^{C^{*}}=\left\{\begin{array}{c}
-\bar{F}^{-1}\left(\frac{c_{\mathrm{LT}}}{c_{\mathrm{RD}}+c_{\mathrm{LD}}}\right)+\frac{\beta\left(c_{\mathrm{RS}}+c_{\mathrm{LS}}-c_{\mathrm{LT}}\right)+E(\varepsilon)-a}{2}<0 \\
\text { if } c_{\mathrm{LD}}+v<c_{\mathrm{LT}} \leq c_{\mathrm{RD}}+c_{\mathrm{LD}} \\
\bar{F}^{-1}\left(\frac{c_{\mathrm{LT}}}{c_{\mathrm{LD}}+v}\right)-\bar{F}^{-1}\left(\frac{c_{\mathrm{LT}}}{c_{\mathrm{RD}}+c_{\mathrm{LD}}}\right)-\frac{\beta\left(w-c_{\mathrm{LS}}-c_{\mathrm{LT}}+\frac{\left(c_{\mathrm{RD}}-v\right) c_{\mathrm{LT}}}{c_{\mathrm{LD}}+v}\right)}{2}<0 \\
\text { if } c_{\mathrm{LT}}<c_{\mathrm{LD}}+v .
\end{array}\right.
\end{aligned}
$$

The conclusion is that $p^{P^{*}}>p^{C^{*}}, T^{P *}<T^{C^{*}}$. Because $\pi_{S}^{C}\left(p^{C}, T^{C}\right)$ is jointly concave in $\left(p^{C}, T^{C}\right)$ and there is unique optimal $\left(p^{C^{*}}, T^{C^{*}}\right)$, then $\pi_{S}^{C}\left(p^{C^{*}}, T^{C^{*}}\right) \geq \pi_{R}^{P}\left(p^{P^{*}}, T^{P^{*}}\right)+\pi_{R}^{P}\left(p^{P^{*}}, T^{P^{*}}\right)$.

(iii) When comparing the decentralized case and the penalty contract:

$$
\begin{aligned}
p^{*}-p^{*}= \begin{cases}\frac{c_{\mathrm{RD}} c_{\mathrm{LT}}}{2 c_{\mathrm{LD}}}-\frac{\left(c_{\mathrm{RD}}-v\right) c_{\mathrm{LT}}}{2\left(c_{\mathrm{LD}}+v\right)}>0 & \text { if } c_{\mathrm{LT}}<c_{\mathrm{LD}} \\
\frac{c_{\mathrm{RD}}-\frac{\left(c_{\mathrm{RD}}-v\right) c_{\mathrm{LT}}}{c_{\mathrm{LD}}+v}}{2}>0 & \text { if } c_{\mathrm{LD}} \leq c_{\mathrm{LT}}<c_{\mathrm{LD}}+v \\
\frac{v}{2}>0 & \text { if } c_{\mathrm{LD}}+v \leq c_{\mathrm{LT}}<c_{\mathrm{RD}}+c_{\mathrm{LD}}\end{cases} \\
T^{P^{*}}-T^{D^{*}}= \begin{cases}\bar{F}^{-1}\left(\frac{c_{\mathrm{LT}}}{c_{\mathrm{LD}}}\right)-\bar{F}^{-1}\left(\frac{c_{\mathrm{LT}}}{c_{\mathrm{LD}}+v}\right)-\left(\frac{c_{\mathrm{RD}} c_{\mathrm{LT}}}{2 c_{\mathrm{LD}}}-\frac{\left(c_{\mathrm{RD}}-v\right) c_{\mathrm{LT}}}{2\left(c_{\mathrm{LD}}+v\right)}<0\right. & \text { if } c_{\mathrm{LT}}<c_{\mathrm{LD}} \\
-\bar{F}^{-1}\left(\frac{c_{\mathrm{LT}}}{c_{\mathrm{LD}}+v}\right)+\frac{\beta\left(c_{\mathrm{RS}}+w+\frac{\left(c_{\mathrm{RD}}-v\right) c_{\mathrm{LT}}}{c_{\mathrm{LD}}+v}\right)+E(\varepsilon)-a}{2}<0 & \text { if } c_{\mathrm{LD}} \leq c_{\mathrm{LT}}<c_{\mathrm{LD}}+v \\
0 & \text { if } c_{\mathrm{LD}}+v \leq c_{\mathrm{LT}}<c_{\mathrm{RD}}+c_{\mathrm{LD}} .\end{cases}
\end{aligned}
$$

Because $\pi_{S}^{C}\left(p^{C}, T^{C}\right)$ is jointly concave in $\left(p^{C}, T^{C}\right)$ and there is unique optimal $\left(p^{C^{*}}, T^{C^{*}}\right)$, then $p^{C^{*}} \leq$ $p^{P^{*}}<p^{D^{*}}, T^{C^{*}} \geq T^{P *}>T^{D^{*}}$,

$$
\left\{\begin{array}{l}
\pi_{S}^{C}\left(p^{C^{*}}, T^{C^{*}}\right)>\pi_{S}^{C}\left(p^{P^{*}}, T^{C^{*}}\right)>\pi_{S}^{C}\left(p^{D^{*}}, T^{C^{*}}\right) \\
\pi_{S}^{C}\left(p^{C^{*}}, T^{C^{*}}\right)>\pi_{S}^{C}\left(p^{C^{*}}, T^{E^{*}}\right)>\pi_{S}^{C}\left(p^{C^{*}}, T^{D^{*}}\right) \\
\pi_{S}^{C}\left(p^{C^{*}}, T^{C^{*}}\right) \geq \pi_{S}^{C}\left(p^{P^{*}}, T^{P^{*}}\right)>\pi_{S}^{C}\left(p^{P^{*}}, T^{D^{*}}\right)>\pi_{S}^{C}\left(p^{D^{*}}, T^{D^{*}}\right) \\
\pi_{S}^{C}\left(p^{P^{*}}, T^{P^{*}}\right)=\pi_{R}^{P}\left(p^{P^{*}}, T^{P^{*}}\right)+\pi_{L}^{P}\left(p^{P^{*}}, T^{P^{*}}\right) \\
>\pi_{S}^{C}\left(p^{D^{*}}, T^{D^{*}}\right)=\pi_{R}^{D}\left(p^{D^{*}}, T^{D^{*}}\right)+\pi_{L}^{D}\left(p^{D^{*}}, T^{D^{*}}\right) .
\end{array}\right.
$$

(iv)

$$
\begin{aligned}
\Delta \pi_{R}^{P} & =\pi_{R}^{P}\left(p^{C^{*}}, T^{C^{*}}\right)-\pi_{R}^{D}\left(p^{D^{*}}, T^{D^{*}}\right) \\
& =\left(p^{C^{*}}-w-c_{\mathrm{RS}}\right)\left(d\left(p^{C^{*}}\right)+E(\varepsilon)\right)+v Q_{2}\left(T^{C^{*}}\right)-\pi_{R}^{D}\left(p^{D^{*}}, T^{D^{*}}\right) .
\end{aligned}
$$


We denote $v_{0}=\frac{\pi_{R}^{D}\left(p^{D^{*}}, T^{D^{*}}\right)-\left(p^{C^{*}}-w-c_{\mathrm{RS}}\right)\left(d\left(p^{C^{*}}\right)+E(\varepsilon)\right)}{Q_{2}\left(T^{C^{*}}\right)}$. When $v \geq v_{0}$, we have $\Delta \pi_{R}^{P} \geq 0$.

$$
\begin{aligned}
\Delta \pi_{L}^{P} & =\pi_{L}^{P}\left(p^{C^{*}}, T^{C^{*}}\right)-\pi_{L}^{D}\left(p^{D^{*}}, T^{D^{*}}\right) \\
& =\left(w-c_{\mathrm{LS}}\right)\left(d\left(p^{C^{*}}\right)+E(\varepsilon)\right)-\left(c_{\mathrm{LD}}+v\right) Q_{2}\left(T^{C^{*}}\right)-c_{\mathrm{LT}} T^{C^{*}}-\pi_{L}^{D}\left(p^{D^{*}}, T^{D^{*}}\right) .
\end{aligned}
$$

We denote $v_{1}=\frac{\left(w-c_{\mathrm{LS}}\right)\left(d\left(p^{C^{*}}\right)+E(\varepsilon)\right)-c_{\mathrm{LD}} Q_{2}\left(T^{C^{*}}\right)-c_{\mathrm{LT}} T^{C^{*}}-\pi_{L}^{D}\left(p^{D^{*}}, T^{D^{*}}\right)}{Q_{2}\left(T^{C^{*}}\right)}$. When $v_{1} \geq v$, we have $\Delta \pi_{L}^{P} \geq 0$.

Proof of Corollary 7.4. The proof is straightforward and is omitted here.

Proof of Proposition 6.3. (i) Based on the time insurance contract:

$$
\left\{\begin{array}{l}
\pi_{R}^{T}=\left(p-w-r-c_{\mathrm{RS}}\right) \int_{0}^{+\infty}(d+\varepsilon) f(\varepsilon) \mathrm{d} \varepsilon-\left(c_{\mathrm{RD}}-w-r\right) \int_{T-d}^{+\infty}(d+\varepsilon-T) f(\varepsilon) \mathrm{d} \varepsilon \\
\pi_{L}^{T}=\left(w-c_{\mathrm{LS}}+r\right) \int_{0}^{+\infty}(d+\varepsilon) f(\varepsilon) \mathrm{d} \varepsilon-\left(c_{\mathrm{LD}}+w+r\right) \int_{T-d}^{+\infty}(d+\varepsilon-T) f(\varepsilon) \mathrm{d} \varepsilon-c_{\mathrm{LT}} T .
\end{array}\right.
$$

The second derivatives of the profits with respect to price and service capacity are assumed to be as follows:

$$
\left\{\begin{array}{l}
\frac{\partial^{2} \pi_{R}^{T}}{\partial p^{2}}=-2 \beta-\left(c_{\mathrm{RD}}-w-r\right) \beta^{2} f(T-d)<0 \\
\frac{\partial^{2} \pi_{L}^{T}}{\partial T^{2}}=-\left(c_{\mathrm{LD}}+w+r\right) f(T-d)<0
\end{array}\right.
$$

Thus, the retailer's and express provider' profits are concave with the retail prices and service capacity. The optimal strategies are $\left(p^{T^{*}}, T^{T^{*}}\right)$.

Based on $\left\{\begin{array}{l}\frac{\partial \pi_{R}^{T}}{\partial p}=0 \\ \frac{\partial \pi_{L}^{T}}{\partial T}=0\end{array}\right.$, we can obtain:

$$
\begin{aligned}
p^{T^{*}} & =\frac{\beta\left(c_{\mathrm{RS}}+w+r+\frac{\left(c_{\mathrm{RD}}-w-r\right) c_{\mathrm{LT}}}{c_{\mathrm{LD}}+w+r}\right)+E(\varepsilon)+a}{2 \beta} \text { and } \\
T^{T^{*}} & =\bar{F}^{-1}\left(\frac{c_{\mathrm{LT}}}{c_{\mathrm{LD}}+w+r}\right)-\frac{\beta\left(c_{\mathrm{RS}}+w+r+\frac{\left(c_{\mathrm{RD}}-w-r\right) c_{\mathrm{LT}}}{c_{\mathrm{LD}}+w+r}\right)+E(\varepsilon)-a}{2} .
\end{aligned}
$$

(ii) When comparing the centralized case and the time insurance contract:

$$
\left\{\begin{array}{l}
p^{T^{*}}-p^{C^{*}}=\frac{w+r-c_{\mathrm{LS}}-c_{\mathrm{LT}}+\frac{\left(c_{\mathrm{RD}}-w-r\right) c_{\mathrm{LT}}}{c_{\mathrm{LD}}+w+r}}{2}>0 \\
T^{T^{*}}-T^{C^{*}}=\left[\bar{F}^{-1}\left(\frac{c_{\mathrm{LT}}}{c_{\mathrm{LD}}+w+r}\right)-\bar{F}^{-1}\left(\frac{c_{\mathrm{LT}}}{c_{\mathrm{LD}}+w+r}\right)-\frac{\beta\left(w+r-c_{\mathrm{LS}}-c_{\mathrm{LT}}+\frac{\left(c_{\mathrm{RD}}-w-r\right) c_{\mathrm{LT}}}{c_{\mathrm{LD}}+w+r}\right)}{2}\right]<0 .
\end{array}\right.
$$

We conclude that $p^{T^{*}}>p^{C^{*}}, T^{T^{*}}<T^{C^{*}}$. Because $\pi_{S}^{C}\left(p^{C}, T^{C}\right)$ is jointly concave in $\left(p^{C}, T^{C}\right)$ and there is a unique optimal $\left(p^{C^{*}}, T^{C^{*}}\right)$, then:

$$
\pi_{S}^{C}\left(p^{C^{*}}, T^{C^{*}}\right) \geq \pi_{R}^{T}\left(p^{T^{*}}, T^{T^{*}}\right)+\pi_{R}^{T}\left(p^{T^{*}}, T^{T^{*}}\right) .
$$

(iii) When comparing the decentralized case and the time insurance contract. If $c_{\mathrm{LT}}<c_{\mathrm{LD}}$, we have

$$
p^{D^{*}}-p^{T^{*}}=\frac{\left(c_{\mathrm{RD}}+c_{\mathrm{LD}}\right)(w+r) c_{\mathrm{LT}}}{2 c_{\mathrm{LD}}\left(c_{\mathrm{LD}}+w+r\right)}-\frac{r}{2}>0
$$




$$
\begin{aligned}
\Leftrightarrow & \left(c_{\mathrm{RD}}+c_{\mathrm{LD}}\right)(w+r) c_{\mathrm{LT}}>c_{\mathrm{LD}}\left(c_{\mathrm{LD}}+w+r\right) r \\
\Leftrightarrow & c_{\mathrm{LD}} r^{2}+\left(c_{\mathrm{LD}}\left(c_{\mathrm{LD}}+w\right)-c_{\mathrm{LT}}\left(c_{\mathrm{RD}}+c_{\mathrm{LD}}\right)\right) r-w c_{\mathrm{LT}}\left(c_{\mathrm{RD}}+c_{\mathrm{LD}}\right)>0 \\
& c_{\mathrm{LD}}>0,-w c_{\mathrm{LT}}\left(c_{\mathrm{RD}}+c_{\mathrm{LD}}\right)<0 .
\end{aligned}
$$

When

$r \in\left[0, \frac{\left(c_{\mathrm{LD}}^{2}+c_{\mathrm{LD}} w-c_{\mathrm{LT}} c_{\mathrm{RD}}-c_{\mathrm{LT}} c_{\mathrm{LD}}\right)+\sqrt{\left(c_{\mathrm{LD}}^{2}+c_{\mathrm{LD}} w-c_{\mathrm{LT}} c_{\mathrm{RD}}-c_{\mathrm{LT}} c_{\mathrm{LD}}\right)^{2}+4 c_{\mathrm{LD}} c_{\mathrm{LT}} w\left(c_{\mathrm{RD}}+c_{\mathrm{LD}}\right)}}{2 c_{\mathrm{LD}}}\right]$,

we have $c_{\mathrm{LD}} r^{2}+\left(c_{\mathrm{LD}}\left(c_{\mathrm{LD}}+w\right)-c_{\mathrm{LT}}\left(c_{\mathrm{RD}}+c_{\mathrm{LD}}\right)\right) r-w c_{\mathrm{LT}}\left(c_{\mathrm{RD}}+c_{\mathrm{LD}}\right)<0 \Leftrightarrow p^{D^{*}}-p^{T^{*}} \geq 0$.

We denote

$$
r_{0}=\frac{\left(c_{\mathrm{LD}}^{2}+c_{\mathrm{LD}} w-c_{\mathrm{LT}} c_{\mathrm{RD}}-c_{\mathrm{LT}} c_{\mathrm{LD}}\right)+\sqrt{\left(c_{\mathrm{LD}}^{2}+c_{\mathrm{LD}} w-c_{\mathrm{LT}} c_{\mathrm{RD}}-c_{\mathrm{LT}} c_{\mathrm{LD}}\right)^{2}+4 c_{\mathrm{LD}} c_{\mathrm{LT}} w\left(c_{\mathrm{RD}}+c_{\mathrm{LD}}\right)}}{2 c_{\mathrm{LD}}}
$$

when $r \in\left[0, r_{0}\right]$, we have

$$
\begin{aligned}
& p^{D^{*}}-p^{T^{*}}=\left\{\begin{array}{ll}
\frac{\left(c_{\mathrm{RD}}+c_{\mathrm{LD}}\right)(w+r) c_{\mathrm{LT}}}{2 c_{\mathrm{LD}}\left(c_{\mathrm{LD}}+w+r\right)}-\frac{r}{2} \geq 0 & \text { if } c_{\mathrm{LT}}<c_{\mathrm{LD}} \\
c_{\mathrm{RD}}-r-\frac{\left(c_{\mathrm{RD}}-w-r\right) c_{\mathrm{LT}}}{c_{\mathrm{LD}}+w+r} \geq 0 & \text { if } c_{\mathrm{LT}} \geq c_{\mathrm{LD}}
\end{array} \quad\right. \text { and } \\
& T^{D^{*}}-T^{T^{*}}= \begin{cases}\bar{F}^{-1}\left(\frac{c_{\mathrm{LT}}}{c_{\mathrm{LD}}}\right)-\bar{F}^{-1}\left(\frac{c_{\mathrm{LT}}}{c_{\mathrm{LD}}+w+r}\right)-\beta\left(\frac{c_{\mathrm{RD}} c_{\mathrm{LT}}}{2 c_{\mathrm{LD}}}-\frac{\left(c_{\mathrm{RD}}-v\right) c_{\mathrm{LT}}}{2\left(c_{\mathrm{LD}}+v\right)}\right) \leq 0 & \text { if } c_{\mathrm{LT}}<c_{\mathrm{LD}} \\
-\bar{F}^{-1}\left(\frac{c_{\mathrm{LT}}}{c_{\mathrm{LD}}+w+r}\right)+\frac{\beta\left(c_{\mathrm{RS}}+w+r+\frac{\left(c_{\mathrm{RD}}-w-r\right) c_{\mathrm{LT}}}{c_{\mathrm{LD}}+w+r}\right)+E(\varepsilon)-a}{2} \leq 0 & \text { if } c_{\mathrm{LD}} \leq c_{\mathrm{LT}} .\end{cases}
\end{aligned}
$$

Because $\pi_{S}^{C}\left(p^{C}, T^{C}\right)$ is jointly concave in $\left(p^{C}, T^{C}\right)$ and there is a unique optimal $\left(p^{C^{*}}, T^{C^{*}}\right)$, then $p^{C^{*}} \leq$ $p^{T^{*}} \leq p^{D^{*}}, T^{C^{*}} \geq T^{T^{*}} \geq T^{D^{*}}$,

$$
\left\{\begin{array}{l}
\pi_{S}^{C}\left(p^{C^{*}}, T^{C^{*}}\right)>\pi_{S}^{C}\left(p^{P^{*}}, T^{C^{*}}\right)>\pi_{S}^{C}\left(p^{D^{*}}, T^{C^{*}}\right) \\
\pi_{S}^{C}\left(p^{C^{*}}, T^{C^{*}}\right)>\pi_{S}^{C}\left(p^{C^{*}}, T^{T^{*}}\right)>\pi_{S}^{C}\left(p^{C^{*}}, T^{D^{*}}\right) \\
\pi_{S}^{C}\left(p^{C^{*}}, T^{C^{*}}\right) \geq \pi_{S}^{C}\left(p^{T^{*}}, T^{T^{*}}\right)>\pi_{S}^{C}\left(p^{T^{*}}, T^{D^{*}}\right)>\pi_{S}^{C}\left(p^{D^{*}}, T^{D^{*}}\right) \\
\pi_{S}^{C}\left(p^{T^{*}}, T^{T^{*}}\right)=\pi_{R}^{T}\left(p^{T^{*}}, T^{T^{*}}\right)+\pi_{L}^{T}\left(p^{T^{*}}, T^{T^{*}}\right) \\
>\pi_{S}^{C}\left(p^{D^{*}}, T^{D^{*}}\right)=\pi_{R}^{D}\left(p^{D^{*}}, T^{D^{*}}\right)+\pi_{L}^{D}\left(p^{D^{*}}, T^{D^{*}}\right) .
\end{array}\right.
$$

(iv)

$$
\begin{aligned}
\Delta \pi_{R}^{T} & =\pi_{R}^{T}\left(p^{C^{*}}, T^{C^{*}}\right)-\pi_{R}^{D}\left(p^{D^{*}}, T^{D^{*}}\right) \\
& =\left(p^{C^{*}}-w-r-c_{\mathrm{RS}}\right)\left(d\left(p^{C^{*}}\right)+E(\varepsilon)\right)+(w+r) Q_{2}\left(T^{C^{*}}\right)-\pi_{R}^{D}\left(p^{D^{*}}, T^{D^{*}}\right) .
\end{aligned}
$$

We denote

$$
\bar{r}_{0}=\frac{\left(p^{C^{*}}-w-c_{\mathrm{RS}}\right)\left(d\left(p^{C^{*}}\right)+E(\varepsilon)\right)+w Q_{2}\left(T^{C^{*}}\right)-\pi_{R}^{D}\left(p^{D^{*}}, T^{D^{*}}\right)}{d\left(p^{C^{*}}\right)+E(\varepsilon)-Q_{2}\left(T^{C^{*}}\right)} .
$$

When $\overline{r_{0}} \geq r$, we have $\Delta \pi_{R}^{T} \geq 0$.

$$
\begin{aligned}
\Delta \pi_{L}^{T}= & \pi_{L}^{T}\left(p^{C^{*}}, T^{C^{*}}\right)-\pi_{L}^{D}\left(p^{D^{*}}, T^{D^{*}}\right) \\
& =\left(w-c_{\mathrm{LS}}+r\right)\left(d\left(p^{C^{*}}\right)+E(\varepsilon)\right)-\left(c_{\mathrm{LD}}+w+r\right) Q_{2}\left(T^{C^{*}}\right)-c_{\mathrm{LT}} T^{C^{*}}-\pi_{L}^{D}\left(p^{D^{*}}, T^{D^{*}}\right) .
\end{aligned}
$$


We denote

$$
\bar{r}_{1}=\frac{\pi_{L}^{D}\left(p^{D^{*}}, T^{D^{*}}\right)-\left(w-c_{\mathrm{LS}}\right)\left(d\left(p^{C^{*}}\right)+E(\varepsilon)\right)+\left(c_{\mathrm{LD}}+w\right) Q_{2}\left(T^{C^{*}}\right)+c_{\mathrm{LT}} T^{C^{*}}}{d\left(p^{C^{*}}\right)+E(\varepsilon)-Q_{2}\left(T^{C^{*}}\right)} .
$$

When $\overline{r_{1}} \leq r$, we have $\Delta \pi_{L}^{T} \geq 0$.

Proof of Corollary 7.5. We have the proof of the

$$
\frac{\partial T^{T^{*}}}{\partial r}=2\left(c_{\mathrm{LD}}+w+r\right)^{4}-c_{\mathrm{LT}} \beta\left(c_{\mathrm{LD}}+w+r\right)^{2}-c_{\mathrm{LT}}^{2} \beta\left(c_{\mathrm{LD}}+c_{\mathrm{RD}}\right) .
$$

If $2\left(\left(c_{\mathrm{LD}}+w+r_{1}\right)^{2}\right)^{2}-c_{\mathrm{LT}} \beta\left(c_{\mathrm{LD}}+w+r_{1}\right)^{2}-c_{\mathrm{LT}}^{2} \beta\left(c_{\mathrm{LD}}+c_{\mathrm{RD}}\right)=0$, we have

$$
\left(c_{\mathrm{LD}}+w+r\right)^{2}=\frac{c_{\mathrm{LT}} \beta+c_{\mathrm{LT}} \sqrt{\beta^{2}+8 \beta\left(c_{\mathrm{RD}}+c_{\mathrm{LD}}\right)}}{4} .
$$

We denote

$$
r_{1}=\frac{\sqrt{c_{\mathrm{LT}} \beta+c_{\mathrm{LT}} \sqrt{\beta^{2}+8 \beta\left(c_{\mathrm{RD}}+c_{\mathrm{LD}}\right)}}}{2} .
$$

If $r \in\left[0, \max \left(0, \sqrt{\left(c_{\mathrm{LD}}+c_{\mathrm{RD}}\right) c_{\mathrm{LT}}}-c_{\mathrm{LD}}-w\right)\right]$, then $\partial p^{T^{*}} / \partial r \leq 0$.

If $r \in\left(\max \left(0, \sqrt{\left(c_{\mathrm{LD}}+c_{\mathrm{RD}}\right) c_{\mathrm{LT}}}-c_{\mathrm{LD}}-w\right), p^{T^{*}}\right]$, then $\partial p^{T^{*}} / \partial r>0$.

Proof of Propositions 8.1 and 8.2. From e-retailer perspective: $\Delta \pi_{R}^{E}=\pi_{R}^{E}\left(p^{C^{*}}, T^{C^{*}}\right)-\pi_{R}^{D}\left(p^{D^{*}}, T^{D^{*}}\right), \Delta \pi_{R}^{P}=$ $\pi_{R}^{P}\left(p^{C^{*}}, T^{C^{*}}\right)-\pi_{R}^{D}\left(p^{D^{*}}, T^{D^{*}}\right), \Delta \pi_{R}^{T}=\pi_{R}^{T}\left(p^{C^{*}}, T^{C^{*}}\right)-\pi_{R}^{D}\left(p^{D^{*}}, T^{D^{*}}\right)$.

When $\Delta \pi_{R}^{E} \geq \Delta \pi_{R}^{P}$, we can obtain

$$
\left(w-p_{0}\right) M^{E^{*}}-w \int_{0}^{M^{f^{*}}-d\left(p^{C^{*}}\right)} F(\varepsilon) \mathrm{d} \varepsilon \geq\left(c_{\mathrm{RD}}+v\right) Q_{2}\left(T^{C^{*}}\right) .
$$

When $\Delta \pi_{R}^{P} \geq \Delta \pi_{R}^{T}$, we can obtain

$$
r\left(d\left(p^{c^{*}}\right)+E(\varepsilon)-Q_{2}\left(T^{C^{*}}\right)\right) \geq(w-v) Q_{2}\left(T^{C^{*}}\right) .
$$

When $\Delta \pi_{R}^{T} \geq \Delta \pi_{R}^{E}$, we can obtain

$$
w \int_{0}^{M^{E^{*}}-d\left(p^{C^{*}}\right)} F(\varepsilon) \mathrm{d} \varepsilon+\left(w+c_{\mathrm{RD}}\right) Q_{2}\left(T^{C^{*}}\right) \geq r\left(d\left(p^{C^{*}}\right)+E(\varepsilon)-Q_{2}\left(T^{C^{*}}\right)\right)+\left(w-p_{0}\right) M^{E^{*}} .
$$

From service provider perspective: $\Delta \pi_{L}^{E}=\pi_{L}^{E}\left(p^{C^{*}}, T^{C^{*}}\right)-\pi_{L}^{D}\left(p^{D^{*}}, T^{D^{*}}\right) \Delta \pi_{L}^{P}=\pi_{L}^{P}\left(p^{C^{*}}, T^{C^{*}}\right)-$ $\pi_{L}^{D}\left(p^{D^{*}}, T^{D^{*}}\right), \Delta \pi_{L}^{T}=\pi_{L}^{T}\left(p^{C^{*}}, T^{C^{*}}\right)-\pi_{L}^{D}\left(p^{D^{*}}, T^{D^{*}}\right)$.

When $\Delta \pi_{L}^{E} \geq \Delta \pi_{L}^{P}$, we can obtain

$$
v Q_{2}\left(T^{C^{*}}\right) \geq\left(w-p_{0}\right) M^{E^{*}}+w \int_{0}^{M^{E^{*}}-d\left(p^{C^{*}}\right)} F(\varepsilon) \mathrm{d} \varepsilon .
$$


When $\Delta \pi_{L}^{P} \geq \Delta \pi_{L}^{T}$, we can obtain

$$
(w+r-v) Q_{2}\left(T^{C^{*}}\right) \geq r\left(d\left(p^{C^{*}}\right)+E(\varepsilon)\right) .
$$

When $\Delta \pi_{L}^{T} \geq \Delta \pi_{L}^{E}$, we can obtain

$$
r\left(d\left(p^{C^{*}}\right)+E(\varepsilon)-Q_{2}\left(T^{C^{*}}\right)\right)+\left(w-p_{0}\right) M^{E^{*}} \geq w Q_{2}\left(T^{C^{*}}\right)-w \int_{0}^{M^{E^{*}}-d\left(p^{C^{*}}\right)} F(\varepsilon) \mathrm{d} \varepsilon .
$$

\section{REFERENCES}

[1] Aliresearch, The research report on e-business in China in 2010. http://www.aliresearch.com/ (Accessed 29 May 2018) (2010).

[2] K.R. Balachandran and S. Radhakrishnan, Quality implications of warranties in a supply chain. Manage. Sci. 51 (2005) $1266-1277$.

[3] A. Chakraborty, S. Maity, S. Jain, S.P. Mondal and S. Alam, Hexagonal fuzzy number and its distinctive representation, ranking, defuzzification technique and application in production inventory management problem. Granular Comput. (2020) $1-15$.

[4] K. Chen and T. Xiao, Outsourcing strategy and production disruption of supply chain with demand and capacity allocation uncertainties. Int. J. Prod. Econ. 170 (2015) 243-257.

[5] X. Chen, Q. Lu and G.G. Cai, Retailer early payment financing in pull supply chains. Social Science Electronic Publishing (2017).

[6] L. Di Corato, C. Dosi and M. Moretto, Multidimensional auctions for long-term procurement contracts with early-exit options: the case of conservation contracts. Eur. J. Oper. Res. 267 (2018) 368-380.

[7] L.M. Ellram, W.L. Tate and C. Billington, Understanding and managing the services supply chain. J. Supply Chain Manage. 40 (2004) $17-32$.

[8] M. Erkoc and S.D. Wu, Managing high-tech capacity expansion via reservation contracts. Prod. Oper. Manage. 14 (2005) $232-251$.

[9] M. Erkoc, H. Wang and A. Ahmed, Optimal capacity investment, and pricing across international markets under exchange rate uncertainty and duopoly competition. Available at SSRN 3152729 (2018).

[10] N. Ghorui, A. Ghosh, E.A. Algehyne, S.P. Mondal and A.K. Saha, AHP-TOPSIS inspired shopping mall site selection problem with fuzzy data. Mathematics 8 (2020) 1380.

[11] L. Guo and X. Wu, Capacity sharing between competitors. Manage. Sci. 64 (2018) 3554-3573.

[12] Y. Hu and Q. Qiang, An equilibrium model of online shopping supply chain networks with service capacity investment. Serv. Sci. 5 (2013) 238-248.

[13] S.A.I. Hussain, U.K. Mandal and S.P. Mondal, Decision maker priority index and degree of vagueness coupled decision making method: a synergistic approach. Int. J. Fuzzy Syst. 20 (2018) 1551-1566.

[14] S.A.I. Hussain, D. Baruah B. Dutta, U.K. Mandal, S.P. Mondal and T. Nath, Evaluating the impact of service quality on the dynamics of customer satisfaction in the telecommunication industry of Jorhat, Assam. Telecommun. Syst. 71 (2019) 31-53.

[15] L. Kong, Z. Li, L. Liang, Y. Xia and J. Xie, A capacity-investment model of wind power with uncertain supply-price under high penetration rate. J. Cleaner Prod. 178 (2018) 917-926.

[16] E. Kusukawa and S. Alozawa, Optimal operation for green supply chain with quality of recyclable parts and contract for recycling activity. Ind. Eng. Manage. Syst. 14 (2015) 248-274.

[17] Z. Lin, C. Cai and B. Xu, Supply chain coordination with insurance contract. Eur. J. Oper. Res. 205 (2010) 339-345.

[18] W. Liu and Y. Wang, Quality control game model in logistics service supply chain based on different combinations of risk attitude. Int. J. Prod. Econ. 161 (2015) 181-191.

[19] W.-H. Liu, D. Xie and X.-C. Xu, Quality supervision and coordination of logistic service supply chain under multi-period conditions. Int. J. Prod. Econ. 142 (2013) 353-361.

[20] W.-H. Liu, X.-C. Xu and A. Kouhpaenejad, Deterministic approach to the fairest revenue-sharing coefficient in logistics service supply chain under the stochastic demand condition. Comput. Ind. Eng. 66 (2013) 41-52.

[21] X. Liu, Q. Gou, L. Alwan and L. Liang, Option contracts: a solution for overloading problems in the delivery service supply chain. J. Oper. Res. Soc. 67 (2016) 187-197.

[22] W. Liu, D. Zhu and Y. Wang, Capacity procurement in logistics service supply chain with demand updating and rational expectation behavior. Asia-Pac. J. Oper. Res. 34 (2017) 1750029.

[23] X. Liu, K. Zhang, B. Chen, J. Zhou and L. Miao, Analysis of logistics service supply chain for the one belt and one road initiative of China. Transp. Res. Part E: Logistics Transp. Rev. 117 (2018) 23-39.

[24] E. Lukas, T. S. Spengler, S. Kupfer and K. Kieckhfer, When and how much to invest? Investment and capacity choice under product life cycle uncertainty. Eur. J. Oper. Res. 260 (2017) 1105-1114. 
[25] S. Maity, S.K. De and S. Prasad Mondal, A study of an EOQ model under lock fuzzy environment. Mathematics 7 (2019) 75.

[26] S. Maity, A. Chakraborty, S.K. De, S.P. Mondal and S. Alam, A comprehensive study of a backlogging EOQ model with nonlinear heptagonal dense fuzzy environment. RAIRO: Recherche Opér. 54 (2020).

[27] S. Maity, S.K. De and S.P. Mondal, A study of a backorder EOQ model for cloud-type intuitionistic dense fuzzy demand rate. Int. J. Fuzzy Syst. 22 (2020) 201-211.

[28] P. Majumder, S.P. Mondal, U.K. Bera and M. Maiti, Application of generalized hukuhara derivative approach in an economic production quantity model with partial trade credit policy under fuzzy environment. Oper. Res. Perspect. 3 (2016) $77-91$.

[29] X. Qin, Q. Su, S.H. Huang, U.J. Wiersma and M. Liu, Service quality coordination contracts for online shopping service supply chain with competing service providers: integrating fairness and individual rationality. Oper. Res. 19 (2019) $269-296$.

[30] J. Qin, K. Wang, Z. Wang and L. Xia, Revenue sharing contracts for horizontal capacity sharing under competition. Ann. Oper. Res. 291 (2020) 731-760.

[31] M. Rahaman, S.P. Mondal, A.A. Shaikh, A. Ahmadian, N. Senu and S. Salahshour, Arbitrary-order economic production quantity model with and without deterioration: generalized point of view. Adv. Differ. Equ. 2020 (2020) 1-30.

[32] M. Rahaman, S.P. Mondal, A.A. Shaikh, P. Pramanik, S. Roy, M.K. Maiti, R. Mondal and D. De, Artificial bee colony optimization-inspired synergetic study of fractional-order economic production quantity model. Soft Comput. 24 (2020) 1534115359.

[33] G. Roels and C.S. Tang, Win-win capacity allocation contracts in coproduction and codistribution alliances. Manage. Sci. 63 (2017) 861-881.

[34] J. Shi and G. Zhang, Multi-product budget-constrained acquisition and pricing with uncertain demand and supplier quantity discounts. Int. J. Prod. Econ. 128 (2010) 322-331.

[35] H. Song and X. Gao, Green supply chain game model and analysis under revenue-sharing contract. J. Cleaner Prod. 170 (2018) 183-192.

[36] S. Tavakoli and A.A. Taleizadeh, An EOQ model for decaying item with full advanced payment and conditional discount. Ann. Oper. Res. 259 (2017) 415-436.

[37] J.A. Van Mieghem, Commissioned paper: capacity management, investment, and hedging: Review and recent developments. Manuf. Serv. Oper. Manage. 5 (2003) 269-302.

[38] X. Wu, P. Kouvelis and H. Matsuo, Horizontal capacity coordination for risk management and flexibility: Pay ex ante or commit a fraction of ex post demand? Manuf. Serv. Oper. Manage. 15 (2013) 458-472.

[39] J. Xie, L. Liang, L. Liu and P. Ieromonachou, Coordination contracts of dual-channel with cooperation advertising in closedloop supply chains. Int. J. Prod. Econ. 183 (2017) 528-538.

[40] L. Xie, J. Ma and H. Han, Implications of stochastic demand and manufacturers' operational mode on retailer's mixed bundling strategy and its complexity analysis. Appl. Math. Modell. 55 (2018) 484-501.

[41] M. Zhang and J. Qin, Coordinate the express delivery supply chain with option contracts. Int. J. Inf. Syst. Supply Chain Manage. (IJISSCM) 9 (2016) 1-21.

[42] J. Zhang, G. Liu, Q. Zhang and Z. Bai, Coordinating a supply chain for deteriorating items with a revenue sharing and cooperative investment contract. Omega 56 (2015) 37-49.

[43] J. Zhang, Q. Gou, F. Yang and L. Liang, Online hot selling period and its impact on e-retailer's pricing strategies. Int. J. Prod. Res. 54 (2016) 1899-1918.

[44] Y. Zhao, T.-M. Choi, T.C. Edwin Cheng, and S. Wang, Supply option contracts with spot market and demand information updating. Eur. J. Oper. Res. 266 (2018) 1062-1071.

[45] S. Zhou, Logistics bottleneck of online retail industry in China. J. Supply Chain Oper. Manage. 11 (2013) 1-11. 